Research Article

\title{
Detecting and Evaluating Defects in Beams by Correlation Coefficients
}

\author{
Thanh Q. Nguyen $\mathbb{D}^{1,2}$ and Hoang B. Nguyen ${ }^{2}$ \\ ${ }^{1}$ Science, Research and Development Department, Ho Chi Minh City University of Transport, Ho Chi Minh City, Vietnam \\ ${ }^{2}$ Ho Chi Minh City University of Transport, Ho Chi Minh City, Vietnam \\ Correspondence should be addressed to Thanh Q. Nguyen; nqthanh@hcmut.edu.vn
}

Received 13 February 2020; Revised 27 January 2021; Accepted 10 February 2021; Published 19 February 2021

Academic Editor: Sinniah Ilanko

Copyright ( 2021 Thanh Q. Nguyen and Hoang B. Nguyen. This is an open access article distributed under the Creative Commons Attribution License, which permits unrestricted use, distribution, and reproduction in any medium, provided the original work is properly cited.

\begin{abstract}
This research proposes a correlation coefficient for detecting and evaluating defects in beams, which brings about a positive outcome in terms of accuracy and efficiency. This parameter surpasses other parameters, such as natural frequency and damping coefficient, thanks to its sensitivity to structural changes. Our results show that although the damping coefficient had more variation than the natural frequency value in the same experiment, its changes were insufficient and unstable at different levels of defects. In addition, the proposed correlation coefficient parameter has a linear characteristic and always changes significantly according to increasing levels of defects. The results outweigh damping coefficient and natural frequency values. Furthermore, this value is always sensitive to measurement channels, which could be an important factor in locating defects in beams. The testing index is statistically evaluated by a normal distribution of the amplitude value of vibration measurement signals. Changes and shifts in this distribution are the basis for evaluating beam defects. Thus, the suggested parameter is a reliable alternative for assessing the defects of a structure.
\end{abstract}

\section{Introduction}

Mathematically, research on detecting defects in bridge beams and other construction components has taken place in two major areas. The first study uses mathematical models to simulate the structures of mechanical systems. Researchers do not focus on characteristics of defects but on their general specifications in terms of kinematic and dynamic responses. The defects caused by changes in geometric dimensions, geometric shapes, or materials might include cracks, such as horizontal cracks [1-4] or vertical cracks $[5,6]$, geometric shapes, $[7,8]$ such as circles, ovals, or obliques, a reduction of mechanical characteristics, such as elastic, torsional, or bending modulus [9-11] or a combination of the above factors. These studies use certain parameters to evaluate the overall stiffness level, $E J_{x}$. The second research area, which seeks to obtain a solution to the inverse problem, is aimed at determining structural characteristics by using algorithms to retrieve relevant information. Some of these algorithms also evaluate the performance of a structure under actual working conditions. In order to increase the accuracy of parameters collected from different measurement signals, researchers have developed different mathematical methods, for example, statistical methods $[12,13]$ or combination with optimization algorithms [14-16], algorithms of artificial neural networks [17-19], wavelet transformation [20, 21], or neuron-fuzz $[15,22]$. Figure 1 shows the steps involved in detecting and forecasting defects in a structure. detail:

The procedure goes from the lowest to highest level, in

(i) Detecting: to inspect and confirm the presence of defects

(ii) Locating: to localize defects

(iii) Evaluating: to assess the impact of these defects on the structure and determine their degrees in order to organize periodic tests and inspection 


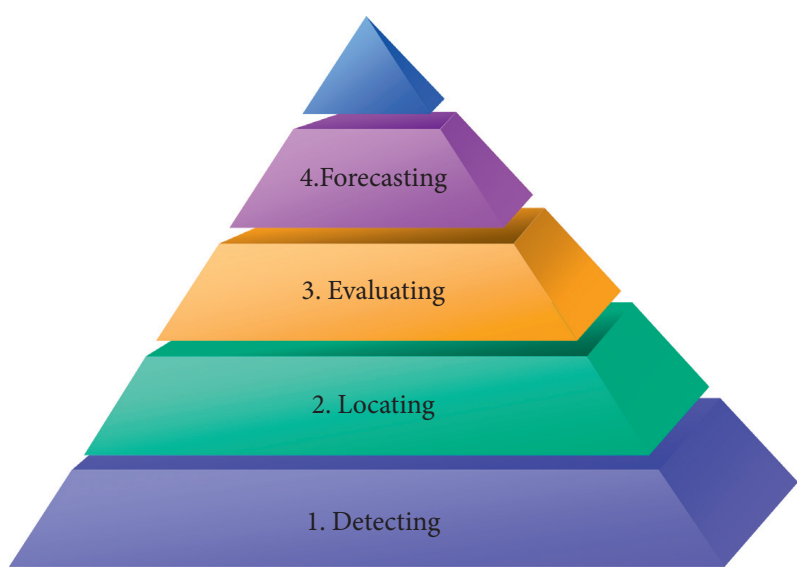

FIgURE 1: The sequence of detecting and evaluating defects.

(iv) Forecasting: to promptly forecast defects, minimizing loss and damage to personnel and assets

As detecting is very important, it has attracted the interest of researchers all over the world. Researchers have mostly opted for relatable signals, such as vibration measurement signals, deformation measurement signals, and transposition signals (deflection).

Some outstanding examples using vibration measurement signals are found in [23, 24]. Parameters related to these signals, such as natural frequencies, mode shapes, vibration amplitudes, and damping coefficients, were commonly used in $[25,26]$; among these, natural frequency was one of the most popular. Many of the above studies have shown that natural frequency does not express changes in the overall stiffness of mechanical systems very well, as it is not sensitive enough in practice. For example, in [27], when the beam had three cracks that accounted for $50 \%$ of its thickness, the natural frequency was reduced by less than $5 \%$. Salawu [28] measured the status of a concrete bridge before and after the trimmer beam was replaced and realized that the frequency of the first six segments changed by $1.7 \%$ on average. The results from Salawu show that natural frequency can only detect relatively large defects but cannot locate them due to the same changes in frequency [29]. Other researchers, such as Loland [30], Fox [31], Meneghetti and Maggiore [32], and Choy et al. [33], also had the same viewpoint [34-38]. Therefore, we must discover new characteristics that are sensitive enough to exploit.

This article proposes a new characteristic built on actual vibration signals and, specifically, on the correlation coefficient. Changes in this parameter are the basis for evaluating the existence and development of defects or locating defects inside structures. Using test beam models, this study not only determines the natural frequencies and damping coefficients of mechanical systems suffering from different extents of defects but also compares their changes to the new proposed parameter using mathematical statistics. In addition, it also defines the normal distribution of vibration measurement signals through experimentation. Most importantly, this new parameter can be applied to complex structural models.

\section{Theoretical Basis}

2.1. Theoretical Vibration of Beam Model. Any vibration in a mechanical system is considered to be a linear combination of basic vibrations. In this investigation, a bar type is used with a basic load-bearing state of compression and tension at the center, bending, torsion, or a combination of different kinds of vibration. However, every vibration can be composed of each type of basic vibration. They are usually represented by the harmonic vibration formula:

$$
w_{i}=W_{i} \cos \left(\omega_{N i} t\right)
$$

in which $\omega_{N i}$ is the $i^{\text {th }}$ natural frequency. Vectors following the order of $W_{i}$ are called $i^{\text {th }}$ private vectors and are assigned so that

$$
\omega_{N 1}<\omega_{N 2}<\omega_{N 3}<, \ldots,<\omega_{N i} .
$$

These values depend on the geometric dimensions of bridge span, material characteristics, and sectional structure. Technically, natural frequency has a special feature: when the frequency of a constraining force is equal to the natural frequency value, the amplitude of the corresponding response will sharply increase due to resonance. Determining the natural frequency of basic vibrations of elastic beams applies the formulas below.

(i) Natural frequency of the bending vibration of a simply supported beam:

$$
\omega_{B i}=(i \pi)^{2} \sqrt{\frac{E J_{z}}{\rho \cdot A \cdot l^{4}}}
$$

in which $l$ is the length of the structure, $E J_{z}$ is its bending stiffness, $A$ is its sectional area, and $\rho$ is its net weight.

(ii) Natural frequency of torsional vibration:

$$
\omega_{T i}=(i \pi) \sqrt{\frac{G J_{z}}{J_{0}}}
$$

in which $G J_{z}$ is the convolution stiffness and $J_{0}$ is the area of the cross-section.

(iii) Natural frequency of torsional-bending vibration:

$$
\omega_{B-T-i}^{2}=\frac{\left(\omega_{T i}^{2}+\omega_{B i}^{2}\right) \pm \sqrt{\left(\omega_{T i}^{2}-\omega_{B i}^{2}\right)^{2}+4 \lambda \omega_{T i}^{2} \omega_{B i}^{2}}}{2(1-\lambda)}
$$

in which $\omega_{B i}^{2}=\left(E I_{z} i^{4} \pi^{4}\right) /\left(l^{4} \rho F\right), \quad \omega_{T i}^{2}=\left(\left(G J_{z} i^{2} \pi^{2} l^{2}+\right.\right.$ $\left.\left.E J_{z} i^{4} \pi^{4}\right) /\left(l^{4} \rho\left(I+F c^{2}\right)\right)\right)$, and $\lambda=\left(F c^{2} /\left(I+F c^{2}\right)\right)$.

When $\lambda=0$, the torsional-bending frequency (5) is determined by

$$
\omega_{B-T-i}^{2}=\frac{\left(\omega_{T i}^{2}+\omega_{B i}^{2}\right) \pm\left(\omega_{T i}^{2}-\omega_{B i}^{2}\right)}{2},
$$


in which $\omega_{B-T-1 i}=\omega_{B-i}$ and $\omega_{B-T-2 i}=\omega_{T-i}$.

Equations (3), (4), and (6) show that if the mechanical system vibrates, the impact of impeding factors will make the amplitude decrease over time. The vibration energy in the system is gradually lost until it vanishes (becomes equal to 0 ). The decreasing energy directly affects the overall stiffness of the beams. However, the natural frequency value rarely changes with respect to the stiffness reduction of structures, which means the energy loss is unable to change the natural frequency value. To evaluate the energy loss mentioned above, researchers focus on examining the damping coefficient. When a mechanical system vibrates under bending, torsion, or a torsional-bending state, the vibration equation is

$$
q(t)=A_{0} e^{-\zeta \omega_{n} t} \cos \left(\sqrt{1-\zeta^{2}} \omega_{n} t-\Phi_{0}\right) .
$$

When a mechanical system suffers from damping vibrations, the natural frequency is reduced. To evaluate the new vibration state (commonly called vibration damping), studies have examined the damping frequency of mechanical systems. $\omega_{d}$ is the damped natural frequency. Therefore,

$$
\omega_{d}=\sqrt{1-\zeta^{2}} \omega_{n} \Leftrightarrow q(t)=A_{0} e^{-\zeta \omega_{n} t} \cos \left(\omega_{d} t-\Phi_{0}\right) .
$$

To determine the damping coefficient $\zeta$, experimental methods record the decreasing vibration graphs of the system. $q_{1}$ and $q_{2}$ represent two adjacent peaks of the decreasing vibration graph (Figure 2). At the recorded time, the two peaks are $t_{1}$ and $t_{2}$. We thus have a ratio:

$$
\frac{q_{1}}{q_{2}}=\frac{A e^{-\zeta \omega_{n} t_{1}} \cos \left(\omega_{d} t_{1}-\Phi_{0}\right)}{A e^{-\zeta \omega_{n} t_{2}} \cos \left(\omega_{d} t_{2}-\Phi_{0}\right)} .
$$

As $q_{1}$ and $q_{2}$ are two adjacent peaks of the graph, $t_{2}=t_{1}+T_{d}$ :

$$
\omega_{d} t_{2}=\omega_{d} t_{1}+\omega_{d} T_{d}=\omega_{d} t_{1}+2 \pi .
$$

Noting equation (10), when applying the damped vibration equation to equation (8), we get the following equation:

$$
\cos \left(\omega_{d} t_{2}-\Phi_{o}\right)=\cos \left(\omega_{d} t_{1}+2 \pi-\Phi_{o}\right)=\cos \left(\omega_{d} t_{1}-\Phi_{o}\right) .
$$

Equation (9) then becomes equation (12). This is the basis for determining energy loss through vibration amplitude:

$$
\frac{q_{1}}{q_{2}}=e^{\zeta \omega_{n} T_{d}} .
$$

The natural logarithm of the above equation is called the logarithmic decrement and is symbolized as $\delta$. This coefficient expresses the loss of energy during vibration as

$$
\delta=\ln \frac{q_{1}}{q_{2}}=\varsigma \omega_{n} T_{d} .
$$

Provided that $\left\{\begin{array}{l}T_{d}=2 \pi / \omega_{d} \\ \omega_{d}=\omega_{n} \sqrt{1-\xi}\end{array}\right.$, the final expression becomes $\delta=\left(2 \pi / \sqrt{1-\zeta^{2}}\right)$.

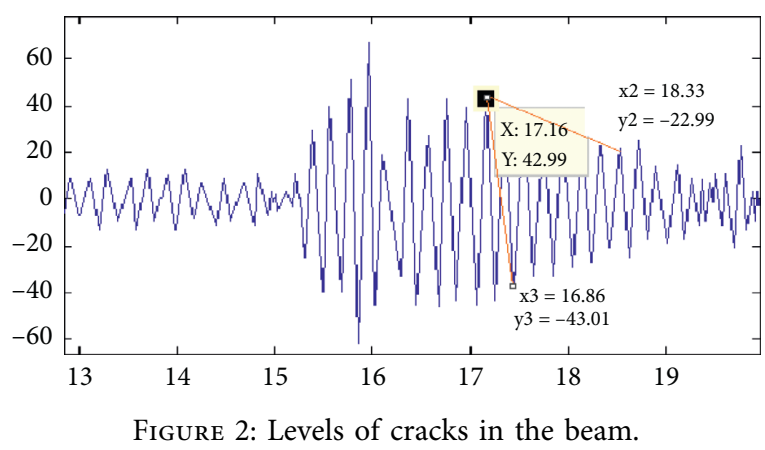

If $\zeta \ll 1$, then the above expression can be written as $\delta \approx 2 \pi \zeta$.

In order to increase the accuracy of determining the $\zeta$ value, instead of two adjacent peaks, we propose to take two peaks at $m$ intervals. Thus, the ratio between $q_{1}$ and $q_{m}$ is

$$
\frac{q_{1}}{q_{1+m}}=\frac{q_{1}}{q_{2}} \cdot \frac{q_{2}}{q_{3}}, \ldots, \frac{q_{m}}{q_{1+m}} .
$$

We combine equation (14) with equation (13) to determine the damping coefficient under all circumstances:

$$
\delta=\frac{1}{m} \ln \left(\frac{q_{1}}{q_{m+1}}\right) .
$$

However, the results of calculating the damping coefficient $\zeta$ usually contain errors. During actual experimentation, we have identified two common cases:

(a) The calculated results have higher values than the reality. This case usually occurs when the test beam is overloaded at a low velocity. In this circumstance, the deflection of the beam suddenly increases to maximum, while the vibration decreases quickly.

(b) The calculated results have smaller values than the reality. This case usually occurs when the beam suffers from forced vibration, with its frequency approaching its natural frequency. The load and velocity on the beam are sufficient to make the bridge vibrate drastically. At that point, the forced vibration lasts longer than the decreasing vibration. As such, the test beam vibrates harshly, and forced vibration in beams creates large vibration amplitudes. This phenomenon causes a deterioration in the bridge capability and destroys the structure.

Therefore, calculating the actual damping value is relatively difficult with remaining deviations. This is why we propose a new parameter to evaluate the energy loss of structural vibration. This parameter must simplify both calculation and measurement.

2.2. Proposal of Correlation Coefficient Model. Correlation coefficients are commonly used in cases of studying the relation between two parameter sets with the same number of samples $\mathrm{X}$ and $\mathrm{Y}$. There are different types of calculations based on usage. The most popular correlation coefficient is the Pearson correlation coefficient, which is calculated by 
dividing the covariances of two variables by their multiplied standard deviations. This calculation is shown as

$$
r=\rho_{X, Y}=\frac{\operatorname{Cov}(X, Y)}{\sigma_{X}, \sigma_{Y}}=\frac{E\left[\left(X-\mu_{X}\right)\left(Y-\mu_{Y}\right)\right]}{\sigma_{X}, \sigma_{Y}},
$$

in which $E$ is the operator of expected value and Cov is the covariance. Another formula is widely applied according to equation (16):

$$
\operatorname{Corr}(X, Y)=\rho_{X, Y}
$$

As

$\mu_{X}=E(X), \sigma X^{2}=E\left[(X-E(X))^{2}\right]=E\left(X^{2}\right)-E^{2}(X)$, and so is $Y$.

On the contrary,

$$
E\left[\left(X-\mu_{X}\right)\left(Y-\mu_{Y}\right)\right]=E(X Y)-E(X) \cdot E(Y) .
$$

Therefore, equation (16) is rewritten as

$$
r=\rho_{X, Y}=\frac{E(X Y)-E(X) E(Y)}{\sqrt{E\left(X^{2}\right)-E^{2}(X)} \cdot \sqrt{E\left(Y^{2}\right)-E^{2}(Y)}} .
$$

The correlation coefficient shall only be defined as above if the standard deviation is bounded and not equal to zero. Mathematically, the correlation coefficient is equal to one in the case of covariant linear correlation and -1 in the case of contravariant linear correlation. Other values ranging from $[-1,1]$ show the level of linear dependence between variables. The closer the correlation coefficients are to -1 and 1 , the stronger the correlation between variables. However, the values in mechanical fields only range between $[0,1]$. It can be concluded that the correlation coefficient is equal to 1 when no energy loss occurs and equal to 0 when no energy exists after vibration transmission.

\section{Experimental Model}

The experimental model was created at the Laboratory of Applied Mechanics (LAM), Ho Chi Minh City University of Technology (Figure 3), utilizing three groups of equipment: a model group, excitation-creating group, and signal-receiving group.

The model group includes a steel plate with a $0.9 \mathrm{~m}$ length, $0.01 \mathrm{~m}$ width, and $0.005 \mathrm{~m}$ height (see Table 1 ) to simulate the load-bearing beam. The steel beam rests on two trimmer beams, as shown in Figure 4(a). Additionally, a deceleration part is installed at each head of the test beam to make the model more realistic. When a vehicle approaches, passes through the beam, and finishes its movement, it does not make the steel beam become tight. To simulate a complicated force acting on the test beam, the study installed one more thin homogeneous plate that creates eccentric vibrations. Thus, this experiment can change not only the running velocity of vehicles but also the rotating velocity of vehicle engines (Figure 4(b)).

The excitation-creating group consists of one engine driven by a belt-drive system. This system lets the vehicle run over the beam in one direction at a steady velocity, as shown in Figure 5(a). When the vehicle moves, the velocity is

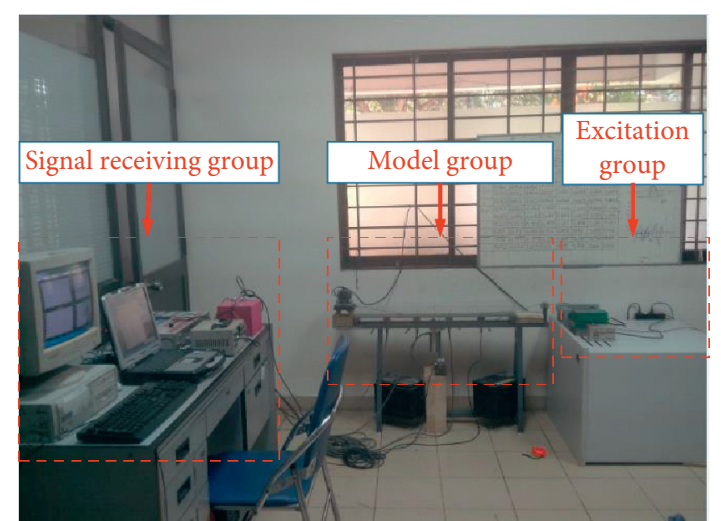

FIGURE 3: Experimental model of travel load on beams (obtained from LAM).

controlled by two inverter machines that can change the rotating velocity of the engine and the running velocity of the vehicles (Figure 5(b)).

The signal-receiving group measures various kinds of parameters, including the velocity, acceleration, deformation, and transposition-meter measurement signals. The transposition meter is directly attached to the middle point of the beam (Figure 6(a)). For vibration signals, parameters from velocity and acceleration sensors were collected. There are four acceleration sensors and four velocity sensors attached to the beam at four locations. The measurement points are distributed evenly on the beam, as shown in Figure 6(b). At each point, we arranged one velocity sensor and one acceleration sensor to simultaneously measure both signals. Finally, a strain gauge was installed at the center of the beam, as shown in Figure 6(c).

The experiment evaluated six different velocities: $\mathrm{V} 50=18.84 \mathrm{~cm} / \mathrm{s}, \quad \mathrm{V} 60=25.12 \mathrm{~cm} / \mathrm{s}, \quad \mathrm{V} 70=28.26 \mathrm{~cm} / \mathrm{s}$, $\mathrm{V} 80=31.4 \mathrm{~cm} / \mathrm{s}, \mathrm{V} 90=35.3 \mathrm{~cm} / \mathrm{s}$, and $\mathrm{V} 100=39.2 \mathrm{~cm} / \mathrm{s}$. Each velocity responded to eight different levels of defects created in the beam (according to Table 2). We treated cracks as defects. At each stage of the experiment, the cracks were deepened, until the beam was nearly destroyed. The moving loads from left abutments to right abutments on the beams and sample parameters are shown in Table 3.

\section{Results and Discussion}

4.1. Stability of Natural Frequency. A power spectrum for the test beam was created, ranging from nondefective to different levels of defects. The results, shown in Figure 7, include Figure 7(a): a free vibration of the intact beam, Figure 7(b): a free vibration of the beam with a $0.4 \mathrm{~mm}$ deep and $0.3 \mathrm{~mm}$ wide crack, Figure $7(\mathrm{c})$ : a free vibration of the beam with a $0.8 \mathrm{~mm}$ deep and $0.3 \mathrm{~mm}$ wide crack, Figure $7(\mathrm{~d})$ : a free vibration of the beam with a $1.2 \mathrm{~mm}$ deep and $0.3 \mathrm{~mm}$ wide crack, Figure $7(\mathrm{e})$ : a free vibration of the beam with a $1.6 \mathrm{~mm}$ deep and $0.3 \mathrm{~mm}$ wide crack, Figure $7(\mathrm{f})$ : a free vibration of the beam with a $2.4 \mathrm{~mm}$ deep and $0.3 \mathrm{~mm}$ wide crack, Figure $7(\mathrm{~g})$ : a free vibration of the beam with a $2.6 \mathrm{~mm}$ deep and $0.3 \mathrm{~mm}$ wide crack, and Figure 7(h): a free vibration of the beam with two defects of 
TABLE 1: Basic parameters of beams.

\begin{tabular}{lc}
\hline Type & Geometric parameters $(l \times d \times w)$ \\
\hline Steel beam & $0.9 \mathrm{~m} \times 0.005 \mathrm{~m} \times 0.1 \mathrm{~m}$ \\
\hline & Accelerometers
\end{tabular}

(a)

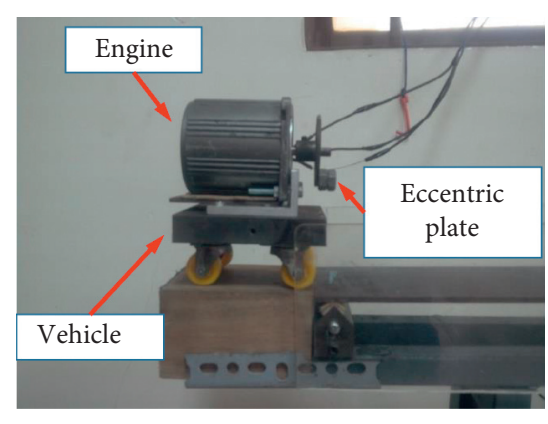

(b)

FIgURE 4: The beam model and the model simulating a vehicle passing though the beam. (a) Beam. (b) Vehicle.

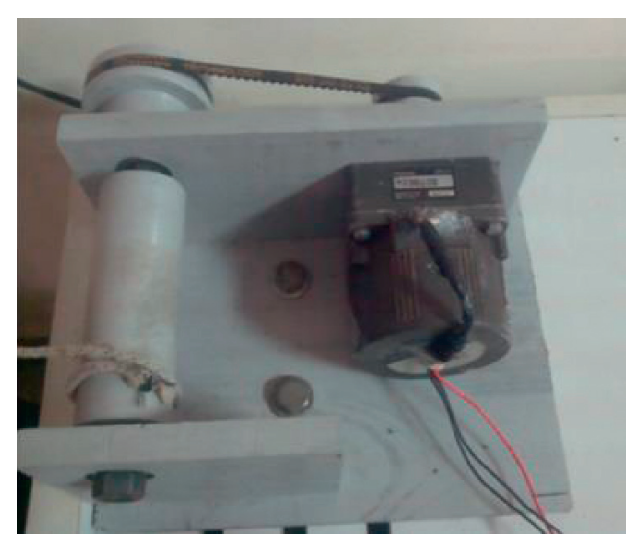

(a)

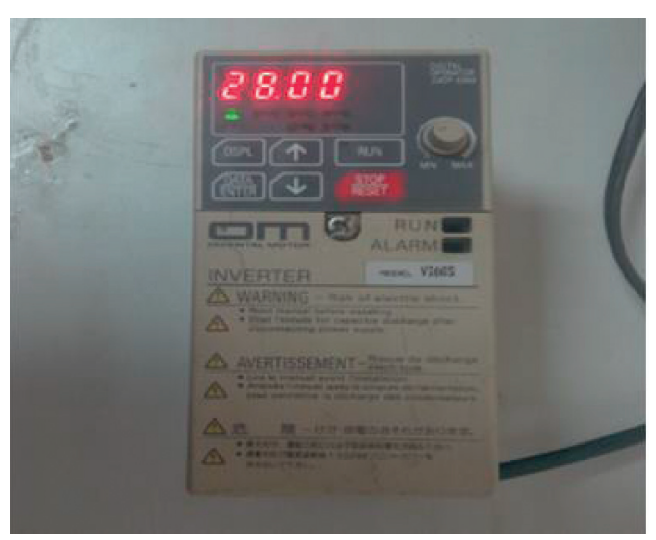

(b)

Figure 5: (a) Transmission and (b) inverter machines from the excitation-creating group.

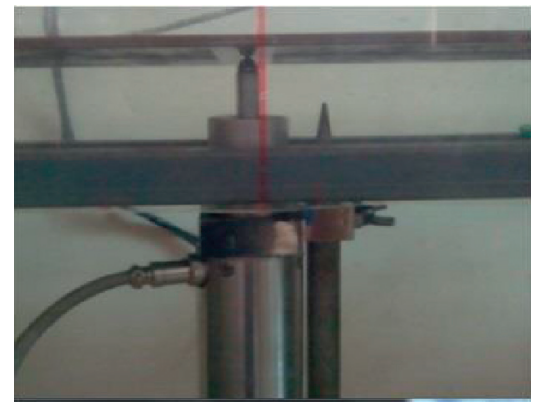

(a)

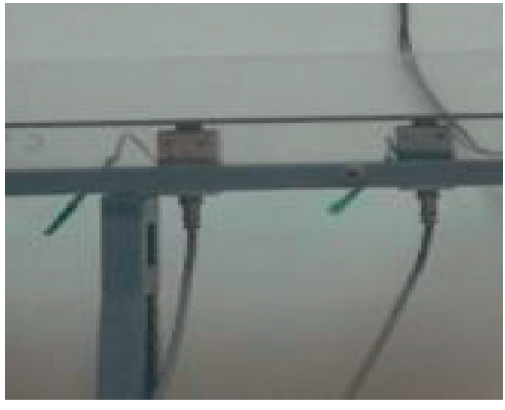

(b)

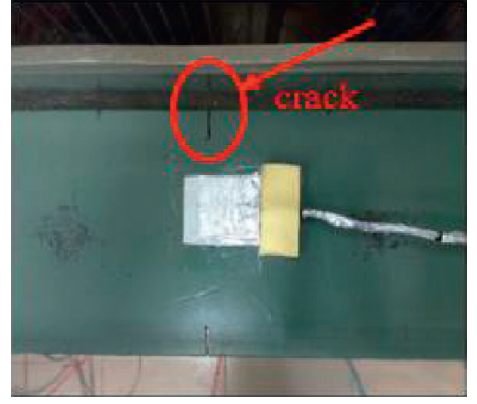

(c)

Figure 6: Continued. 


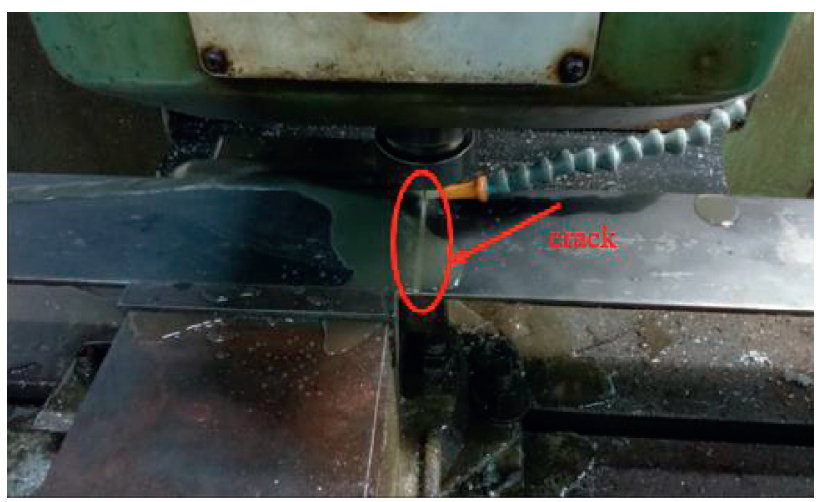

(d)

FIgURE 6: Sensors installed on test beam: (a) displacement sensor; (b) accelerometer; (c) strain-gauge; (d) the position of the cut.

TABLE 2: Levels of cracks in the beam.

\begin{tabular}{lccc}
\hline No. & Label & Depth of crack $(\mathrm{mm})$ & Width of crack $(\mathrm{mm})$ \\
\hline 1 & $\mathrm{H}_{0}$ & 0 & 0 \\
2 & $\mathrm{H}_{4}$ & 0.4 & 0.3 \\
3 & $\mathrm{H}_{8}$ & 0.8 & 0.3 \\
4 & $\mathrm{H}_{12}$ & 1.2 & 0.3 \\
5 & $\mathrm{H}_{16}$ & 1.6 & 0.3 \\
6 & $\mathrm{H}_{20}$ & 2.0 & 0.3 \\
7 & $\mathrm{H}_{24}$ & 2.4 & 0.3 \\
8 & $\mathrm{H}_{26}$ & 2.6 & 0.3 \\
\hline
\end{tabular}

TABLE 3: Sample signal parameters.

Sample frequency

Time to collect a file

Total measurement points

Number of files in a measurement point

Number of samples in a measurement point

Total samples in four measurement points
100 sample/seconds

1,920 seconds

4 measurement points

96

192,000 sample 960,000 sample

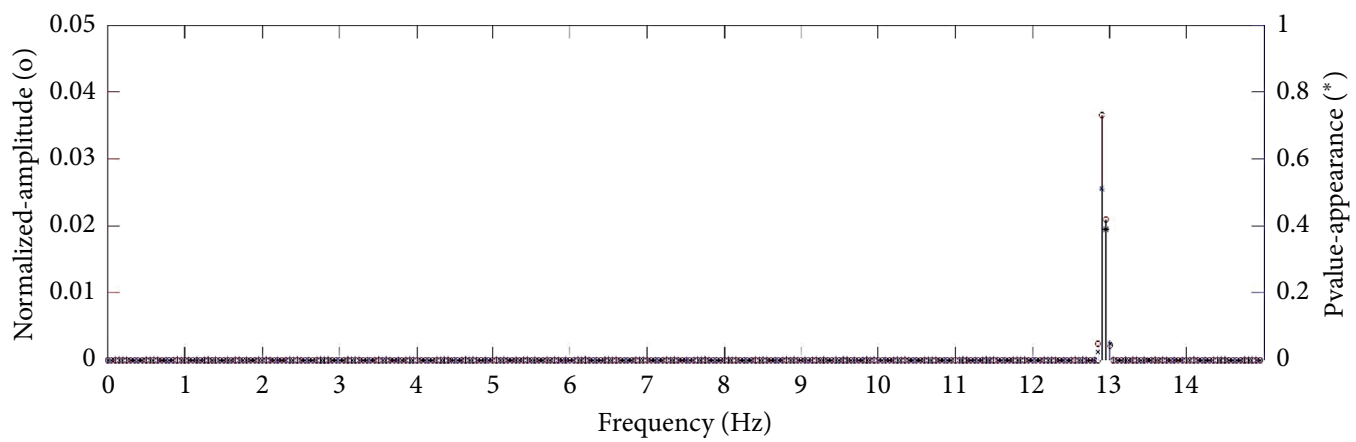

(a)

Figure 7: Continued. 


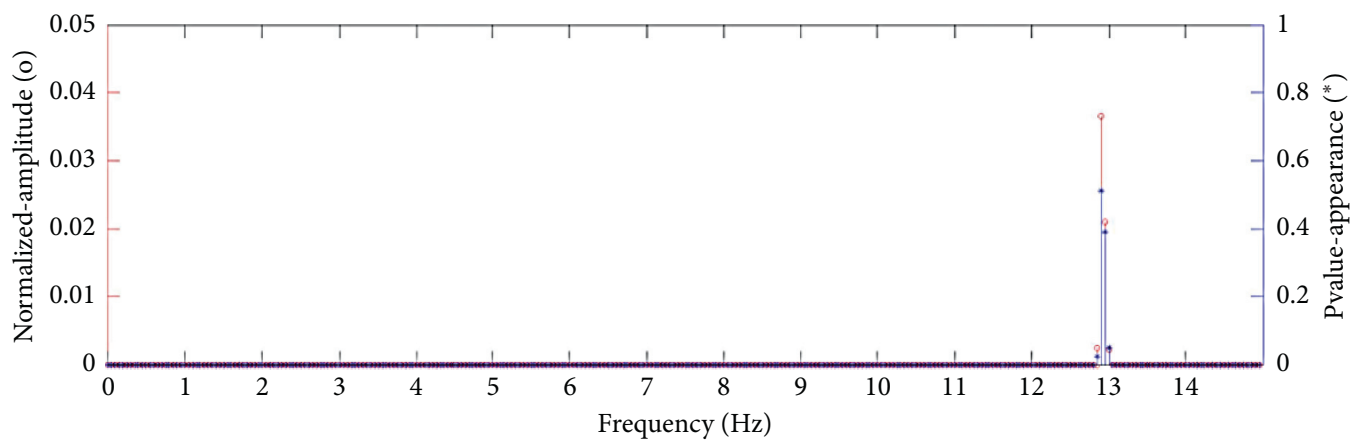

(b)

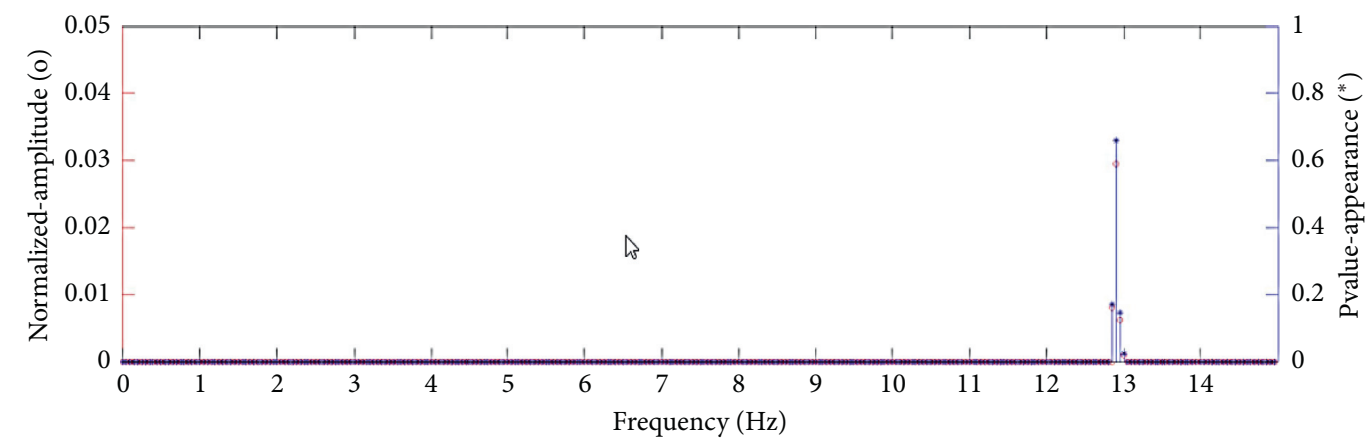

(c)

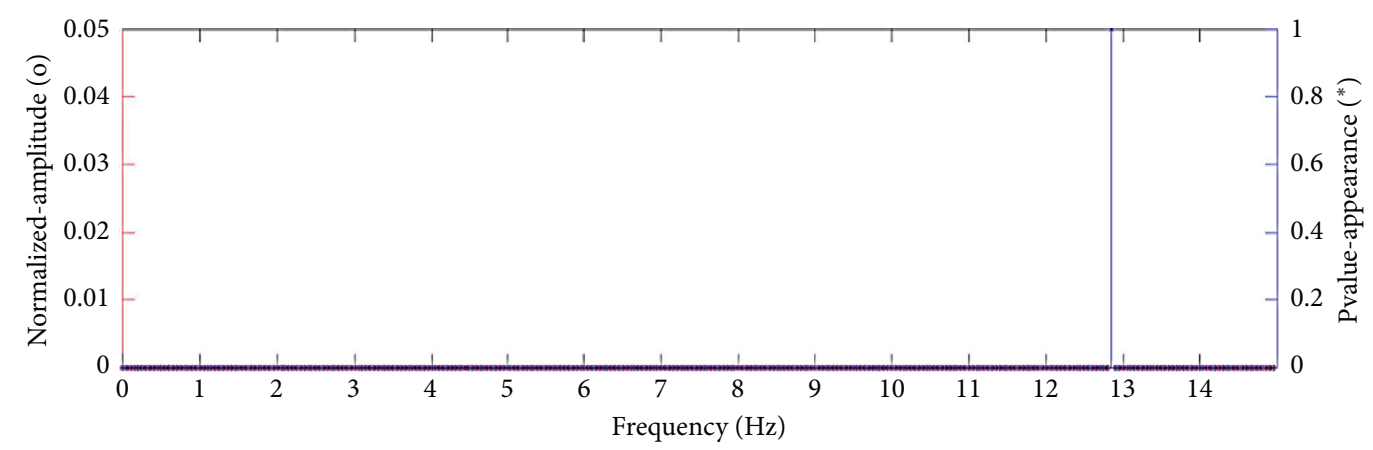

(d)

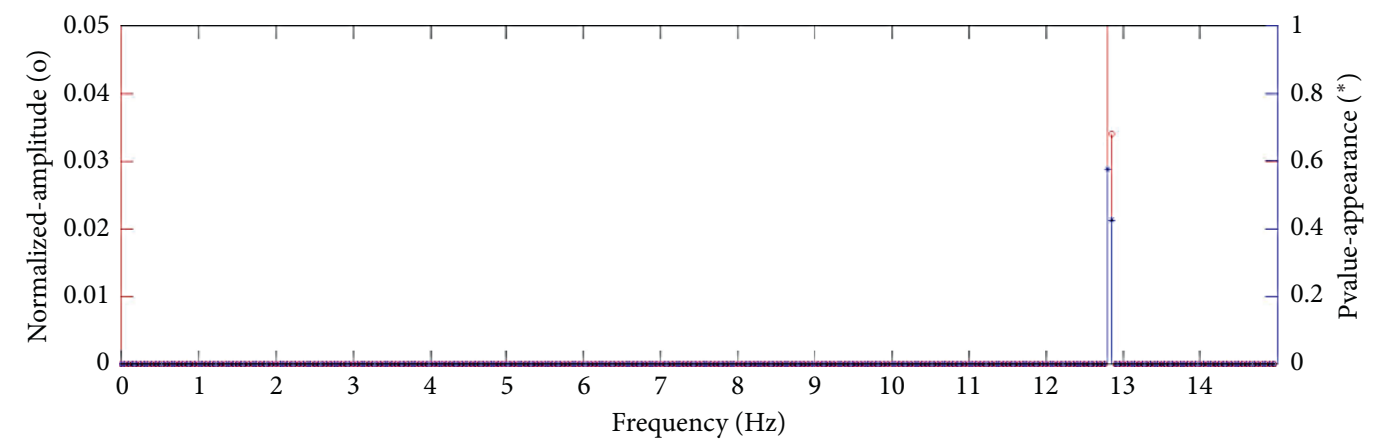

(e)

Figure 7: Continued. 


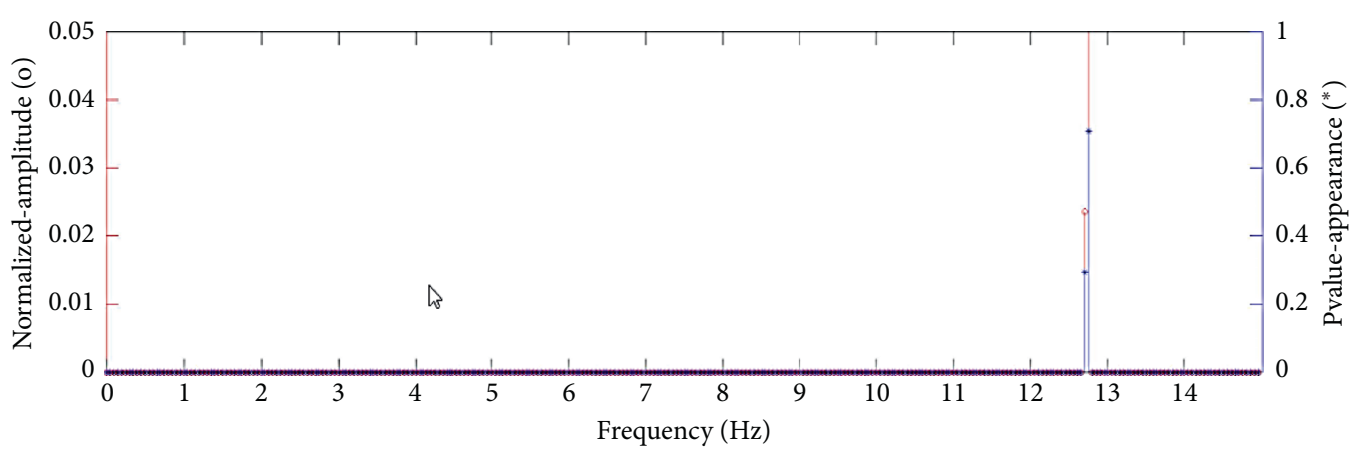

(f)

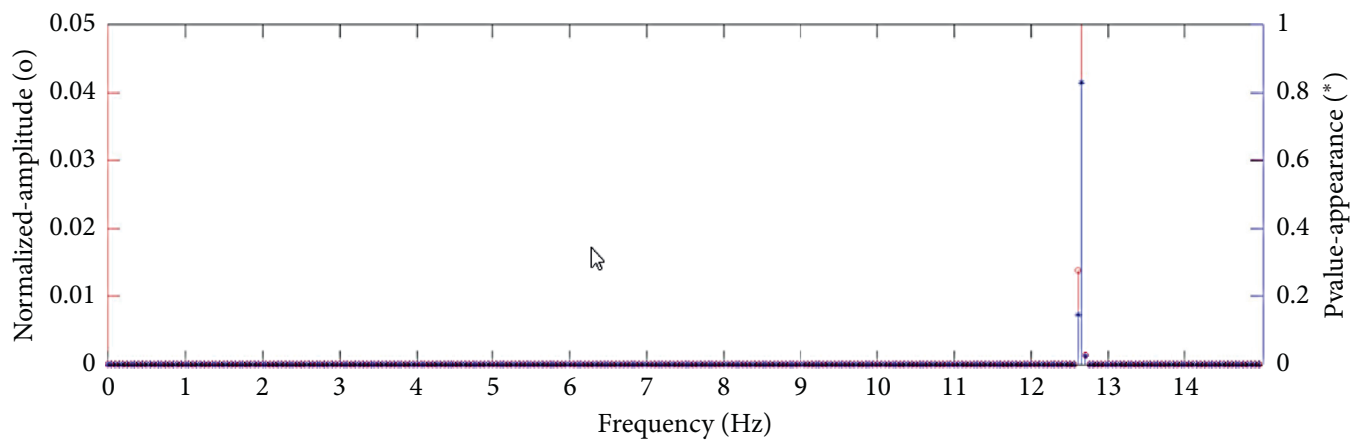

(g)

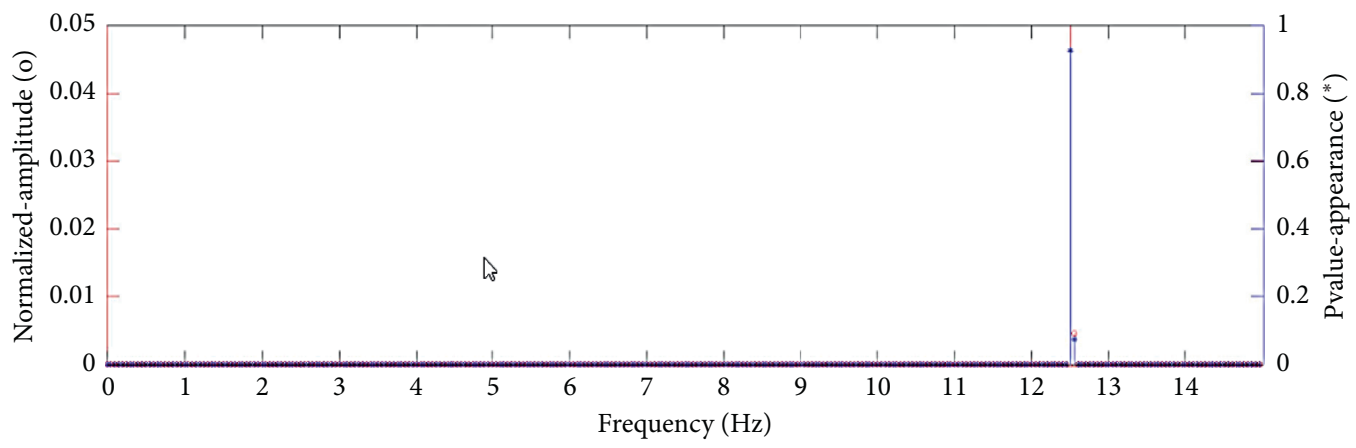

(h)

FIgURE 7: Natural frequencies of the free vibration beam corresponding to different levels of defects.

$0.3 \mathrm{~mm}$ width wherein the first crack is $2.6 \mathrm{~mm}$ deep and the second crack is $0.8 \mathrm{~mm}$ deep.

Changes in the natural frequency value were too small (not exceeding 4\%) during the experiment. They were not adequate for determining the existence of defects in the beam. Furthermore, under free vibration, not only one natural frequency but also others nearby on the spectrum appeared. These frequencies had almost identical values (with only a $0.05 \mathrm{~Hz}$ differential), and the amplitudes of different spectra corresponded to different levels of cracks. The natural frequency tended to continuously reduce together with the levels of cracks. However, this reduction was too small in comparison with the changes in the defects. From the intact level (beam with no crack) to the maximum level of defect (H26), the value of the frequency was reduced by no more than $0.5 \mathrm{~Hz}$. Therefore, changes in natural frequency cannot evaluate, locate, or determine the level of defects in the beam.
Figures $8(\mathrm{a})-8(\mathrm{~h})$ show the frequency values of the power spectra under forced action when the vehicle model passes through the beam. These values correspond to the levels of defects (as shown in Table 2) at different velocities $(\mathrm{V} 50=18.84 \mathrm{~cm} / \mathrm{s}, \quad \mathrm{V} 60=25.12 \mathrm{~cm} / \mathrm{s}, \quad \mathrm{V} 70=28.26 \mathrm{~cm} / \mathrm{s}$, $\mathrm{V} 80=31.4 \mathrm{~cm} / \mathrm{s}, \quad \mathrm{V} 90=35.3 \mathrm{~cm} / \mathrm{s}$, and $\mathrm{V} 100=39.2 \mathrm{~cm} / \mathrm{s}$ ). When the vehicle moved on the beam, together with a basic natural frequency (determined when the beam vibrates freely), there were more forced frequencies, such as $f_{1}=6.2 \mathrm{~Hz}, f_{2}=7.8 \mathrm{~Hz}, f_{3}=9.4 \mathrm{~Hz}$, and $f_{4}=10.8 \mathrm{~Hz}$, and higher frequencies beyond the natural frequency value. Corresponding to different levels of defects, the natural frequency remains nearly unchanged, which is similar to the free vibration of beams. This result accords with prior research $[27,28,39,40]$. Most researchers conclude that changes in natural frequency are not sensitive enough to determine a partial breakdown of the test or actual beams. The problem is the accuracy of measurement equipment: it is 


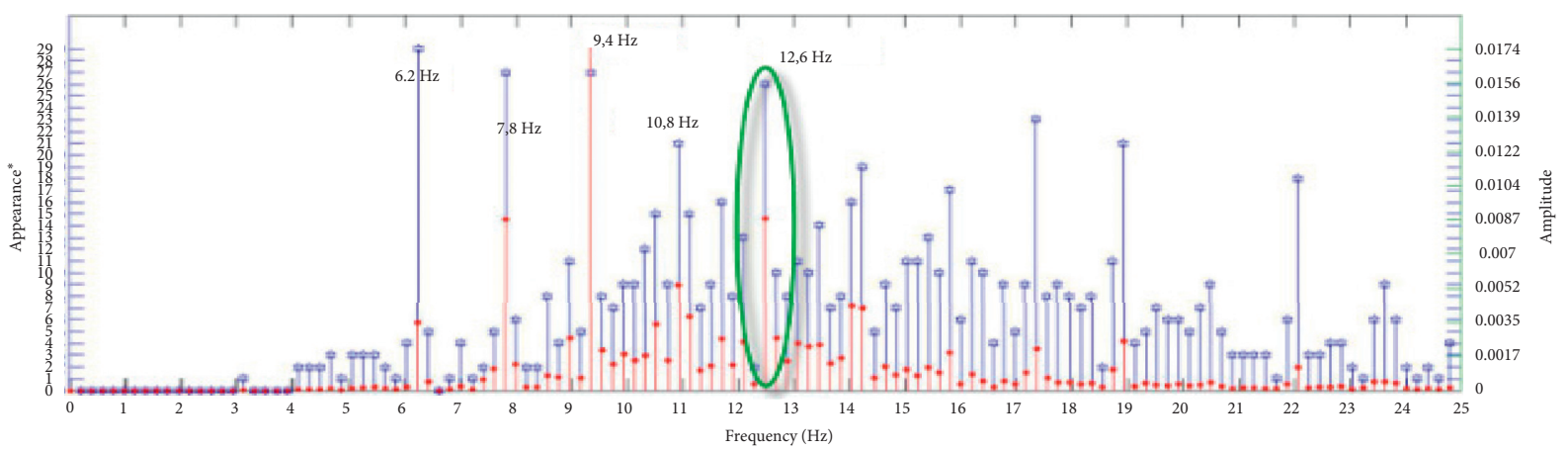

(a)

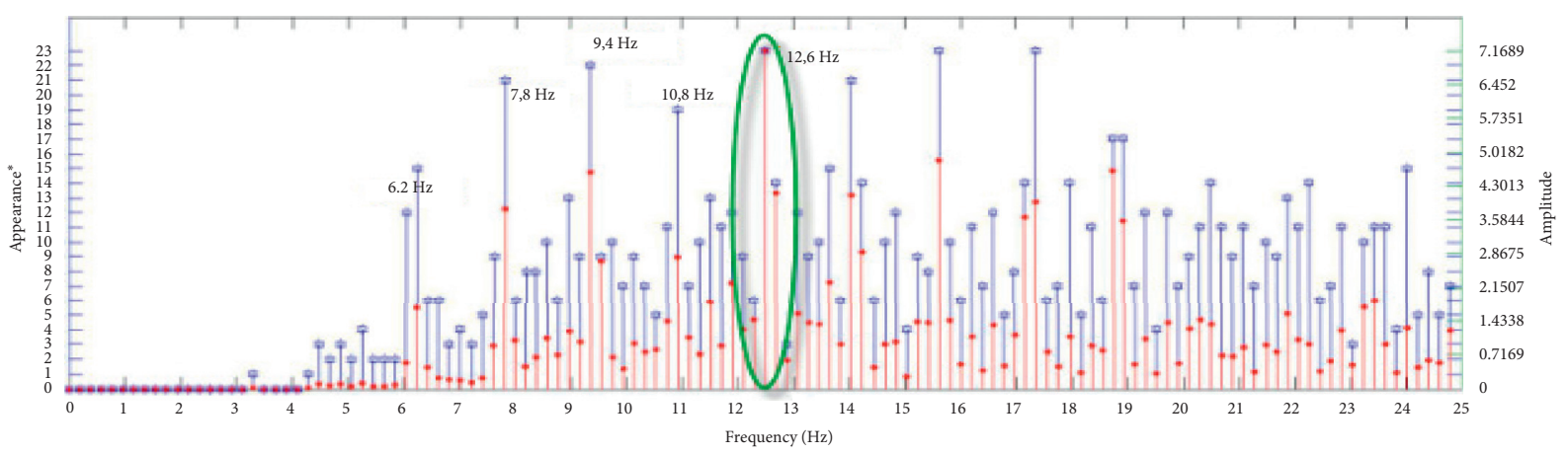

(b)

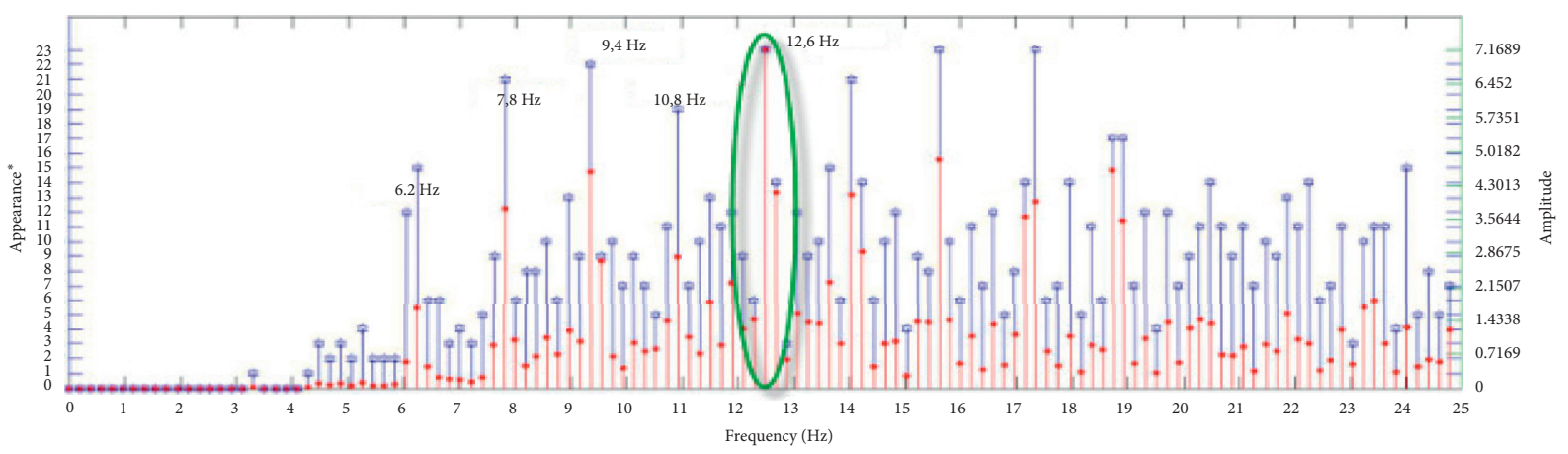

(c)

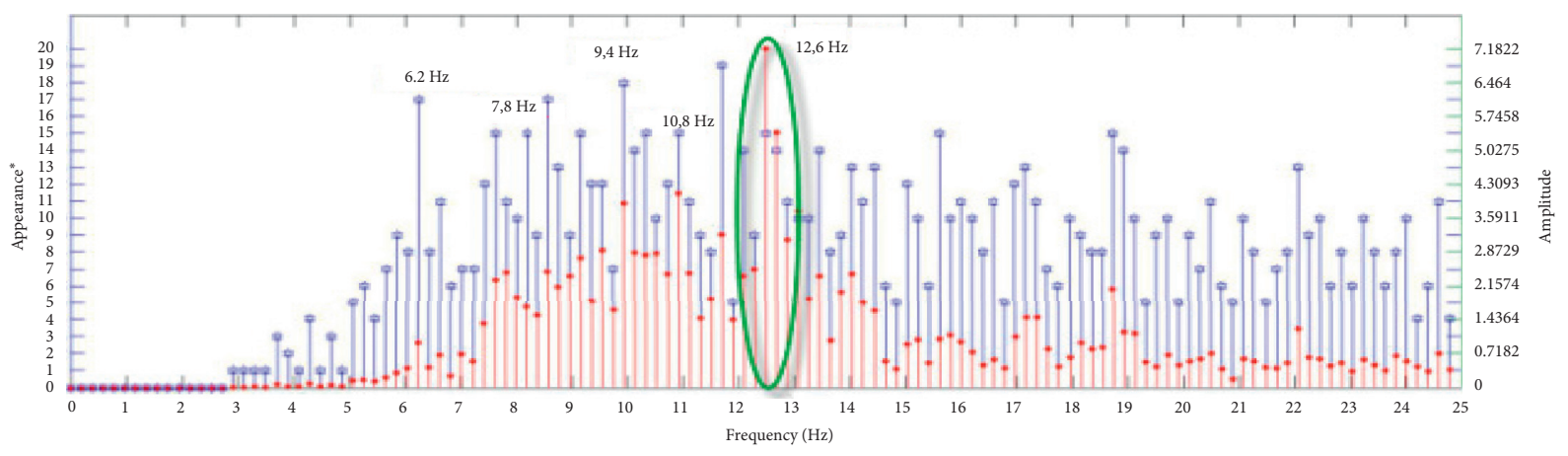

(d)

Figure 8: Continued. 


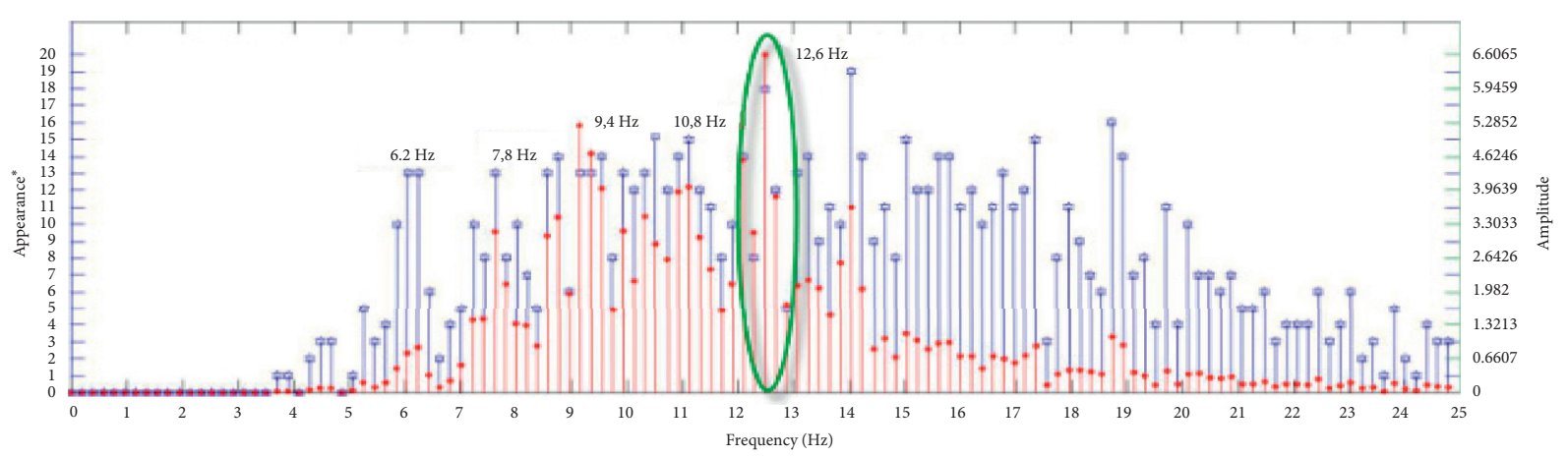

(e)

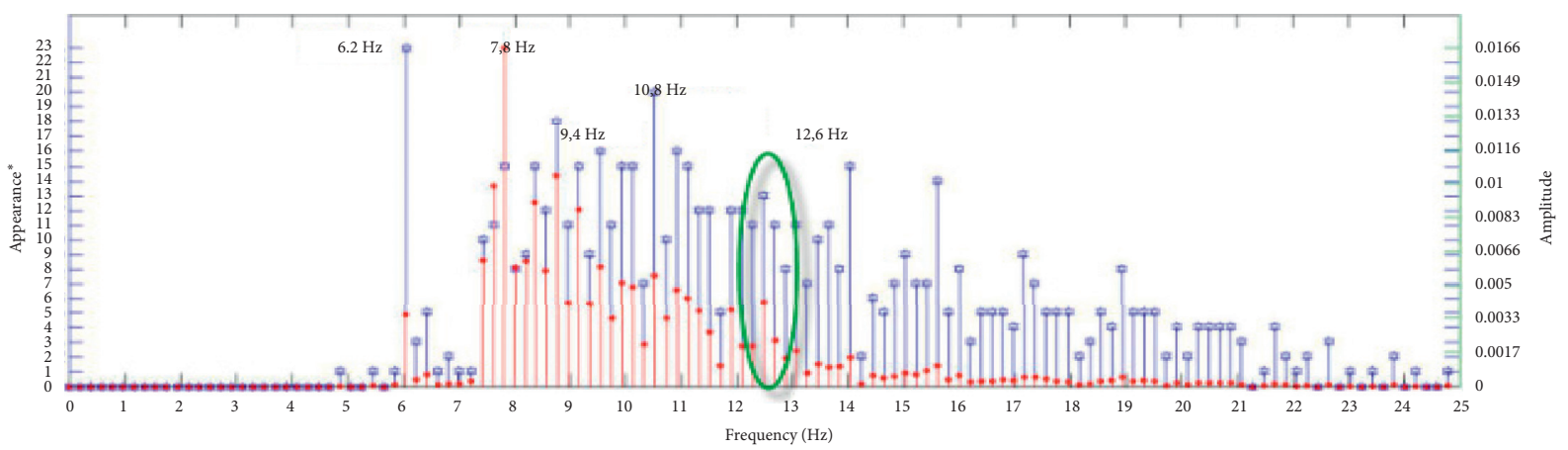

(f)

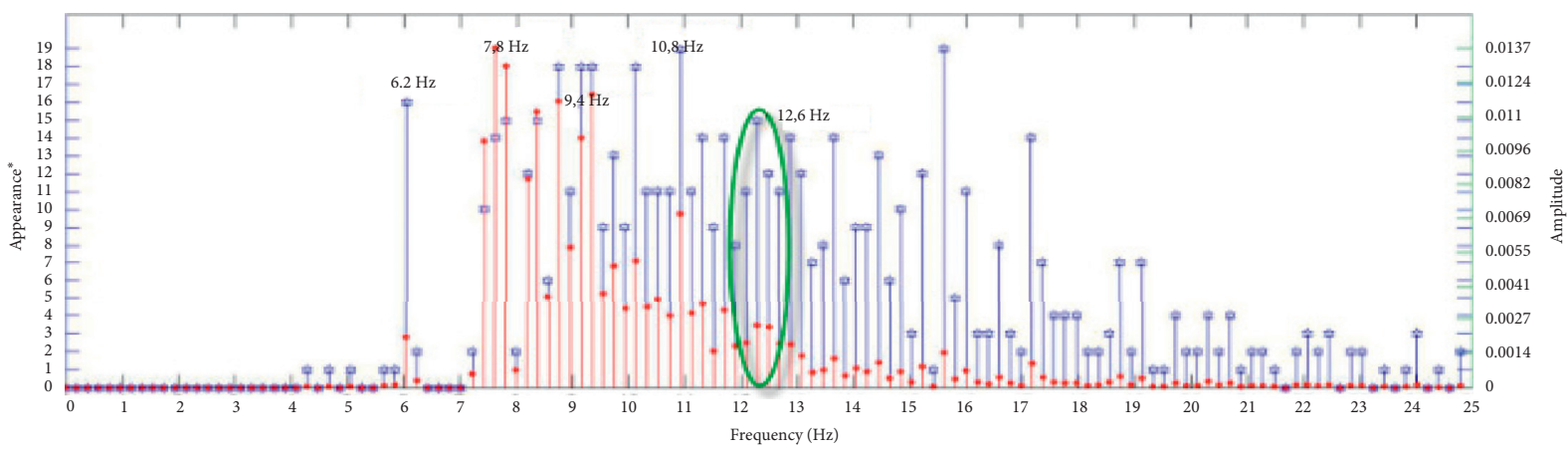

(g)

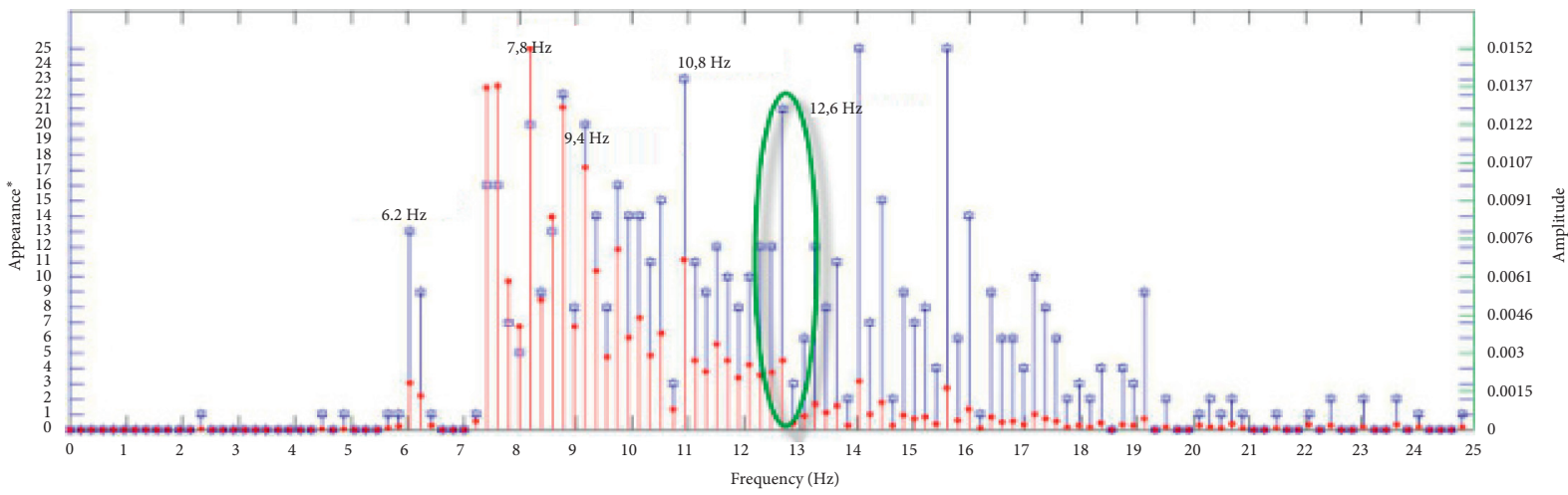

(h)

FIGURE 8: Natural frequencies of the beam under acting vehicular force corresponding to different levels of defect. 
unable to spot these small differences. Furthermore, frequency is an overall quantity: it is not sensitive to partial changes. Thus, natural frequency does not provide enough information on structural changes.

4.2. Changes of Damping Coefficient. This research also studied changes in damping components at different levels of defects. In general, damping coefficients collected from vibrations of sensors always vary in a similar way. The results show that

(i) From defect level $\mathrm{H}_{0}$ to level $\mathrm{H}_{12}$, the damping coefficient tended to increase and reached a maximum value of 0.3 . This change was relatively larger and more distinct than natural frequency values, as shown in Figures 9-14. However, under different circumstances of defects, such as $\mathrm{H}_{16}$, the value was reduced to 0.15 , lower than that of the intact beam (with no defect). Further investigation showed that this coefficient increased slightly until level $\mathrm{H}_{26}$, where the beam was entirely destroyed. Moreover, there was no difference in damping coefficients at each measurement point (sensor location) according to Table 3.

(ii) The velocity of the experiment did not significantly affect the value of the damping. Figures 9-14 show the damping coefficient values at six different velocities corresponding to each level of defects.

In general, the change in the damping coefficient is insufficient and unstable. Therefore, we can hardly recognize the existence of defects, especially in beams suffering from major defects. In addition, the changes in the damping coefficients at four measurement points were relatively the same, which made it difficult to locate cracks in the beam. Although it performs better than natural frequency, the damping coefficient is still an impractical, low-sensitivity parameter. This conclusion is accepted in other studies $[25,26]$, in which the damping coefficient value is affected by the mechanical characteristics of the material. The structural changes in the experimental models only have impacts on small parts, not the whole beam structure.

\subsection{Changes in Correlation Coefficient}

4.3.1. Changes in Correlation Coefficient. Due to insufficient damping coefficients and natural frequencies, we propose to use correlation coefficients. Both Figure 15 and Table 2 show the relation between two measurements (Figure 4(a)) channels through correlation coefficients. The new proposed parameter has always shown a significant linear change corresponding to the increase in defect degree. According to Figure 15, when correlation coefficients decreased, the level of cracks was found to have increased. They decreased within the range of $[1,0]$. If the correlation coefficient is equal to 1 , there is perfect correlation. This usually happens to correlation coefficients of measurements at the same point (autocorrelation). On the contrary, when the correlation coefficient between two points is equal to 0 , there is no binding relation. In terms of energy distribution in beams, the reduction of correlation coefficients implies energy loss at each level of defects. The correlation coefficient is influenced by velocities during the experiment. This means that the velocity in the experimental model scatters the vibrating energy. It changes the fluctuating values of consecutive elements. As defined in the draft, the more the value of the velocity increased, the more the value of the correlation coefficient decreased. In the manuscript, we want to define the relationship between these two parameters (correlation coefficient value and experimental velocity). Hence, the existence of defects is the main reason for this loss. In each case, we have the following comments:

(i) Figure 15 shows changes in correlation coefficients between channel 1 and the remaining channels. The value of channel 1 had significant changes compared with other channels (100\%), from a nondefective level to defect level $\mathrm{H}_{26}$. This change is the rule and remains steady throughout the extent of defects. It also surpasses the results of the damping coefficient and natural frequency values. This research will delve into the effective usage of this parameter at different levels of defects.

(ii) Figures 16-18 show changes in correlation values in channel 2 compared with the remaining channels as well as in channel 3 with the remaining channels. The results indicate the symmetric characteristics of the two measurement channels throughout different levels. In other words, the distribution of measurement channels in the model can affect this value during evaluation. Therefore, this value is sensitive to the measurement channel and crucial for locating defects in the beam. Similar conclusions can be made upon investigating the correlation values of channels $\mathrm{R}_{1-4}$ (between channel 1 and channel 4) and channels $\mathrm{R}_{4-1}$ (between channel 4 and channel $1)$.

(iii) When the velocity changed, the correlation coefficients sped up rapidly (Figures 15-18). This suggests that the relation between correlation coefficients and velocity corresponds linearly to each level of defects. The impact of velocity on this parameter increased the feasibility of detecting defects, as it can show the overall condition of a structure under acting force.

4.3.2. The Relation between Correlation Coefficients and Defects. Corresponding to different levels of defects, correlation coefficients are distributed in pairs as follows:

(i) Regarding the value of correlation coefficients between two consecutive channels $\left(\mathrm{R}_{1-2}\right.$ and $\left.\mathrm{R}_{3-4}\right)$ without cracks, Figure 19 shows almost no connection with the levels of cracks in the beam. When the cracks were at the highest level $\left(\mathrm{H}_{26}\right)$ and V100 velocity, the changes in channel $\mathrm{R}_{1-2}$ were approximately $40 \%$ in comparison with the intact beam. The change was nearly $38 \%$ in channel $R_{3-4}$. 


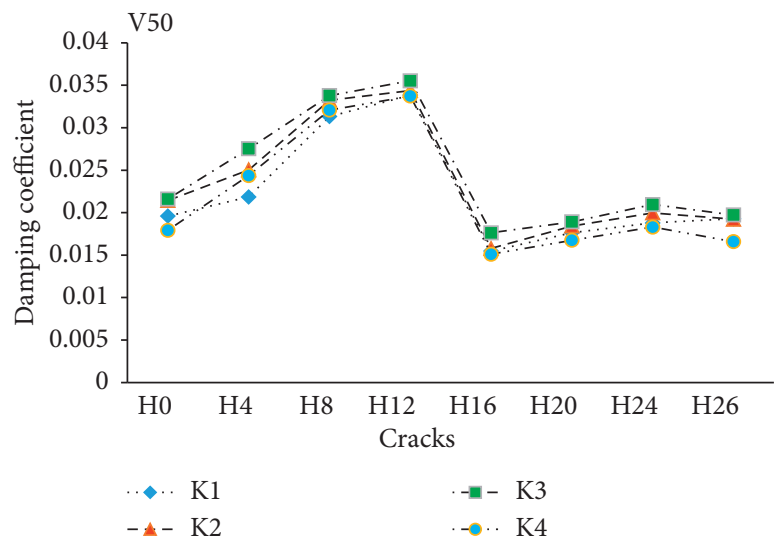

FIGURE 9: Damping coefficients under acting vehicular force (V50) corresponding to different levels of defects.

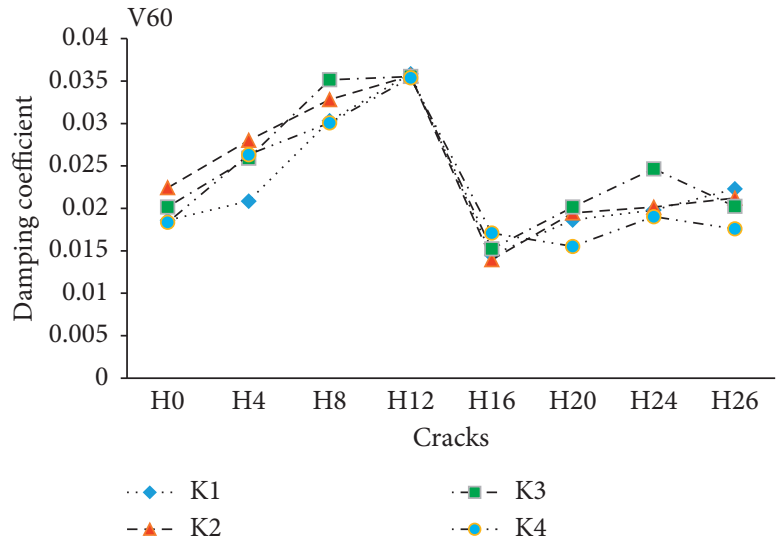

Figure 10: Damping coefficients under acting vehicular force (V60) corresponding to different levels of defects.

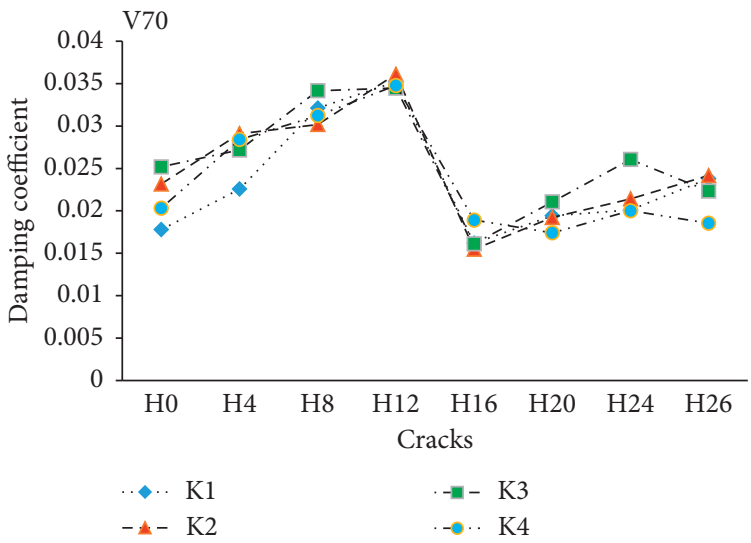

Figure 11: Damping coefficients under acting vehicular force (V70) corresponding to different levels of defects.

The distribution of the correlation coefficient rule in these similar channels is equivalent and relatively linear at each level of cracks. This is the standard input for evaluating the presence of cracks in beams.

(ii) Regarding the correlation coefficient values of two consecutive channels $\left(\mathrm{R}_{2-3}\right)$ with cracks (Figure 20$)$, the correlation value changed quickly according to the increase in the cracks. This change was significant (over 90\%) between the intact beams after they reached the level $\left(\mathrm{H}_{26}\right)$ at V100 velocity. In the first $\left(\mathrm{R}_{1-2}\right.$ and $\left.\mathrm{R}_{3-4}\right)$ and second $\left(\mathrm{R}_{2-3}\right)$ circumstances with the same level of defects, the changes were sufficient for determining the location of the cracks in the beam.

(iii) Regarding the correlation coefficients of two channels that were far away from each other $\left(R_{1-3}\right.$ 


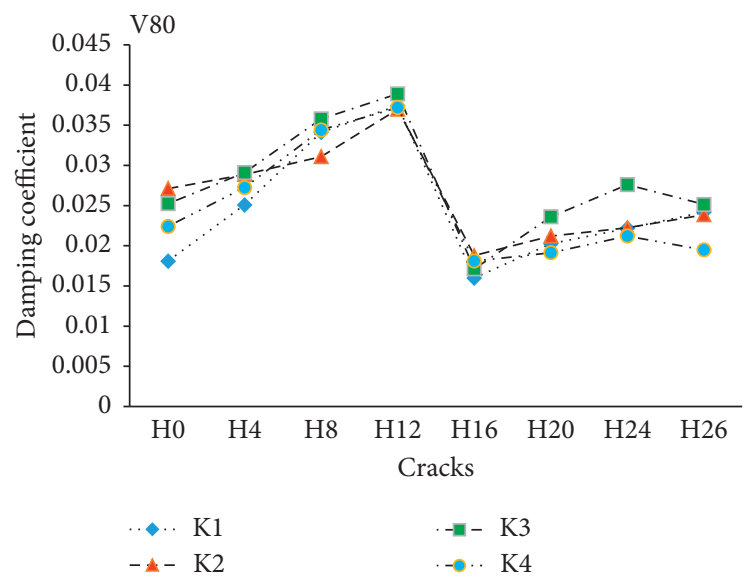

Figure 12: Damping coefficients under acting vehicular force (V80) corresponding to different levels of defects.

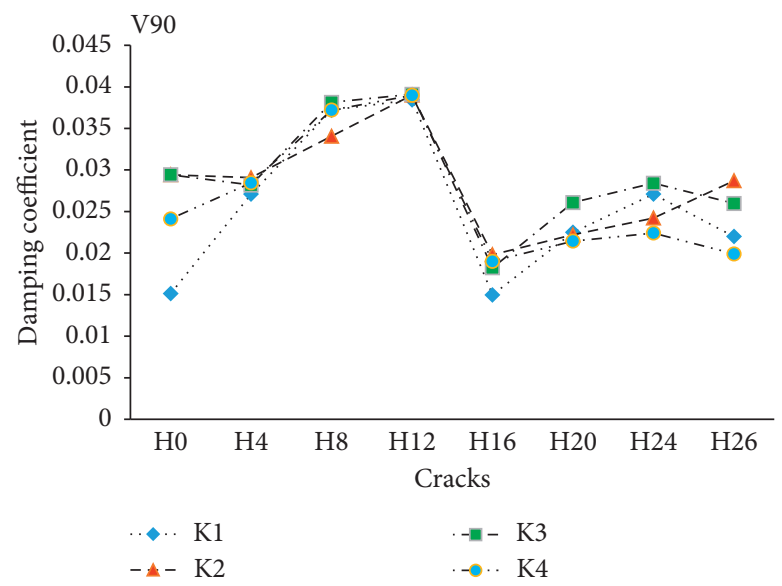

FIGURE 13: Damping coefficients under acting vehicular force (V90) corresponding to different levels of defects.

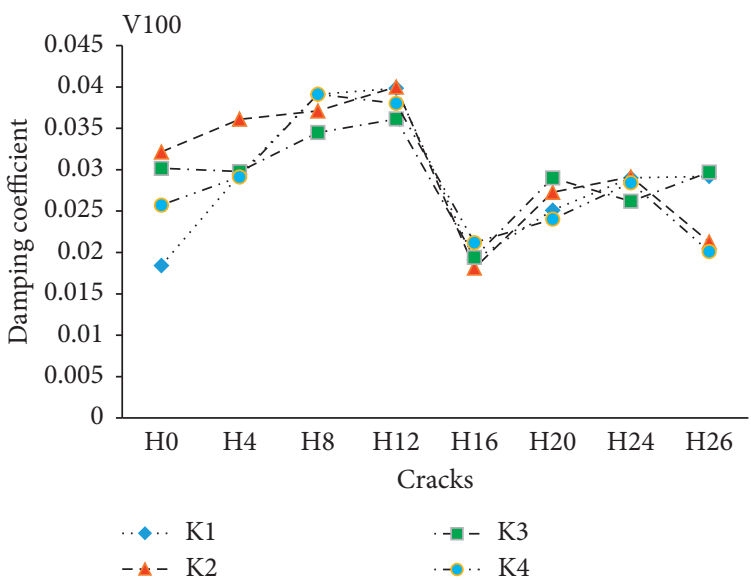

FigURE 14: Damping coefficients under acting vehicular force (V100) corresponding to different levels of defects.

and $\mathrm{R}_{2-4}$ ) (see Figure 21) with defects in between, their values among these channels were relatively different. Under forced vibration, the vibration energy was transmitted from channel 1 to channel 2 , passing through the defect and finally to channel 3 . As analyzed above, the energy was partially lost during transmission from one point to another according to the direction of vibration. It 

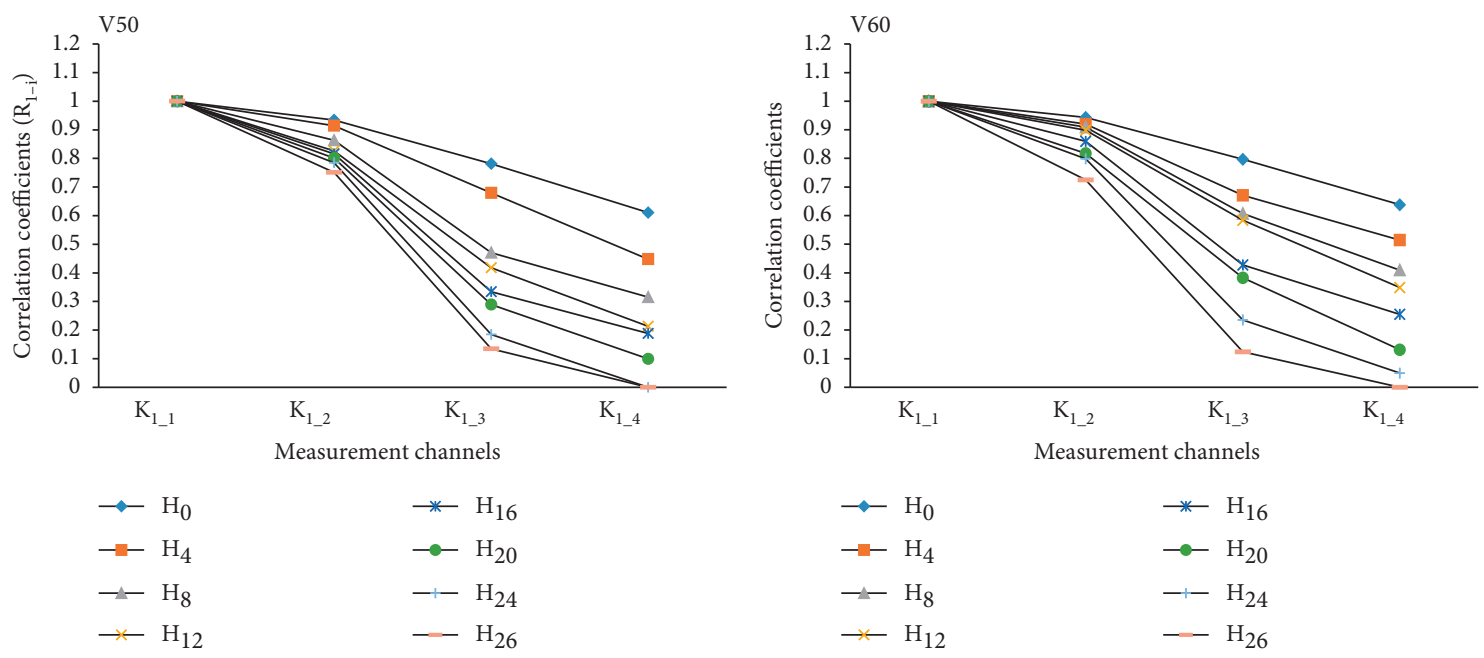

(a)

(b)
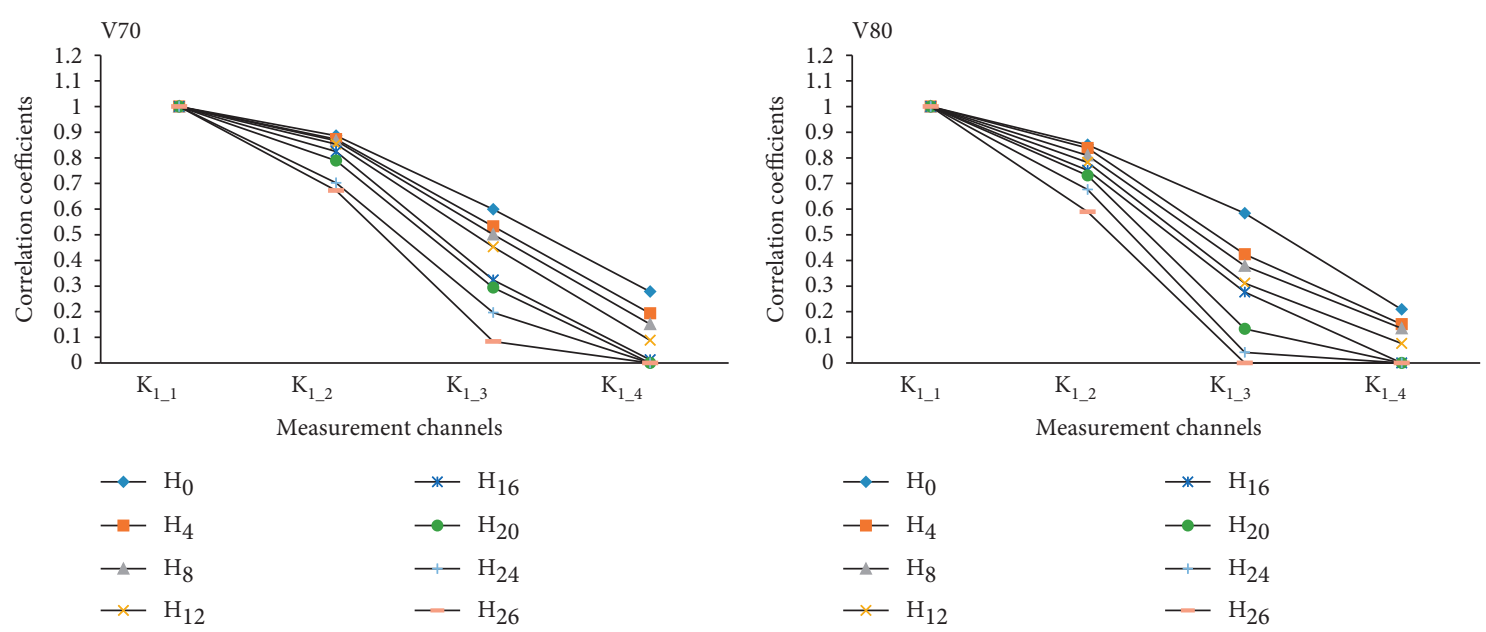

(c)

(d)

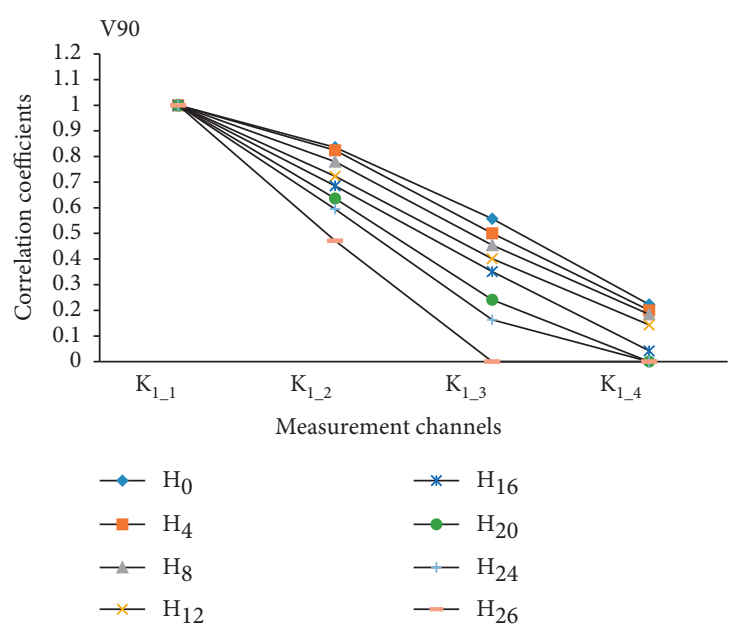

(e)

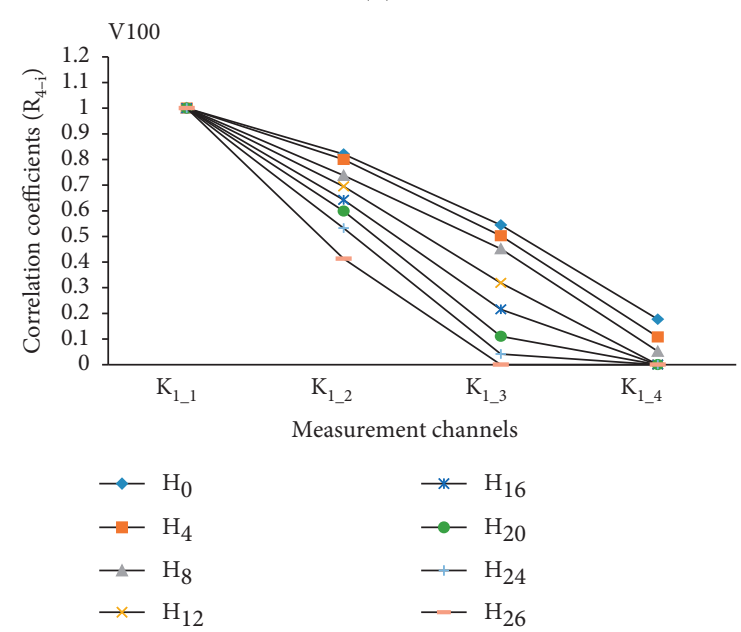

(f)

FIGURE 15: Changes of correlation coefficients $\mathrm{R}_{1-i}$ (between channel 1 and the remaining channels) corresponding to the levels of defects and different velocities. 


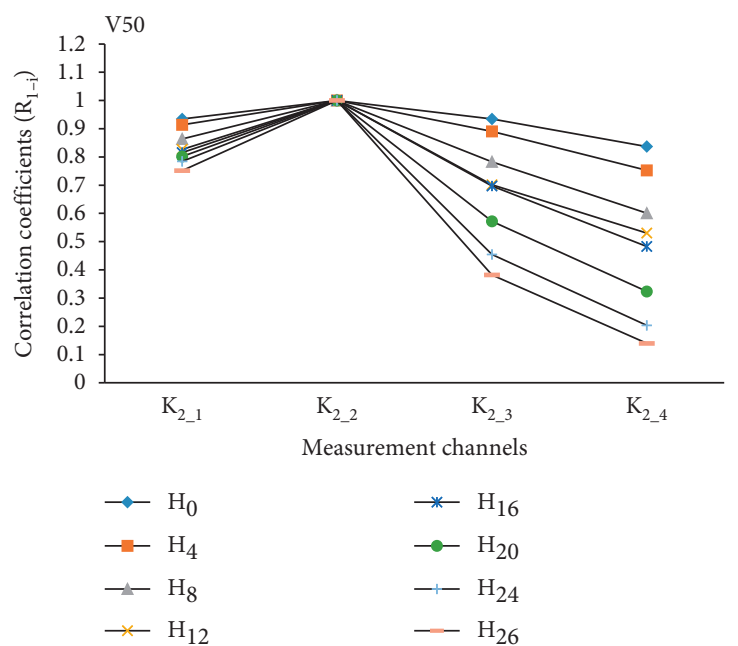

(a)

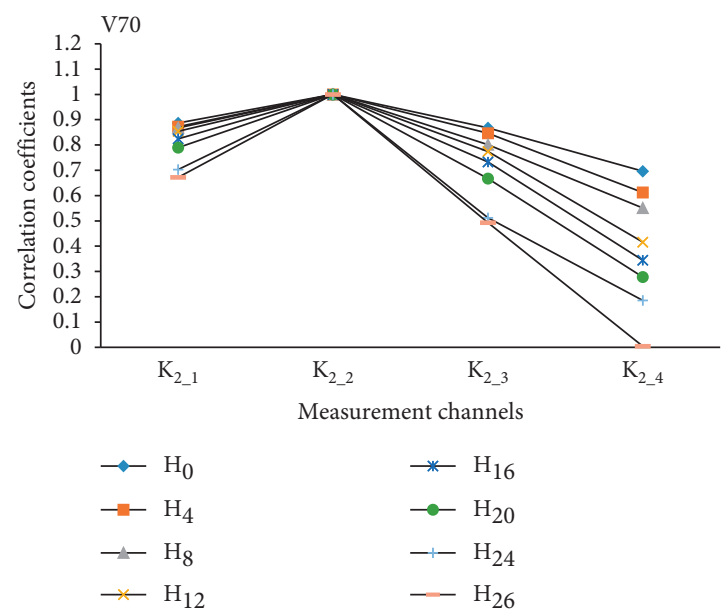

(c)

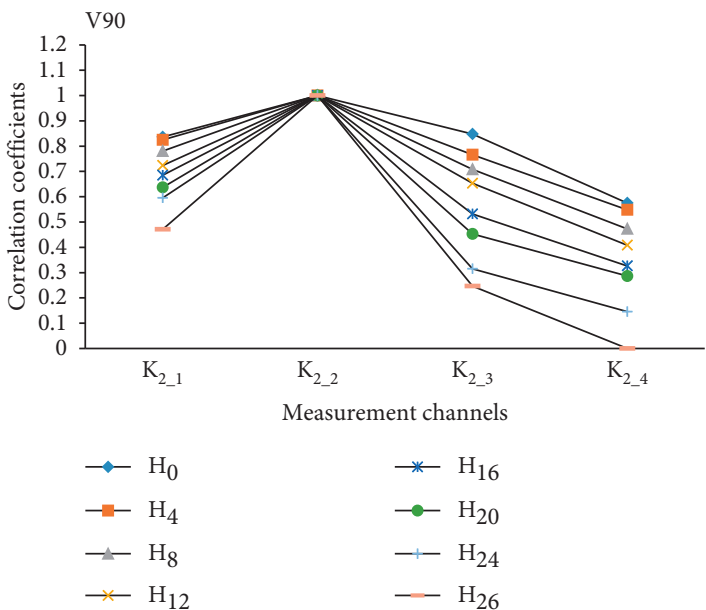

(e)

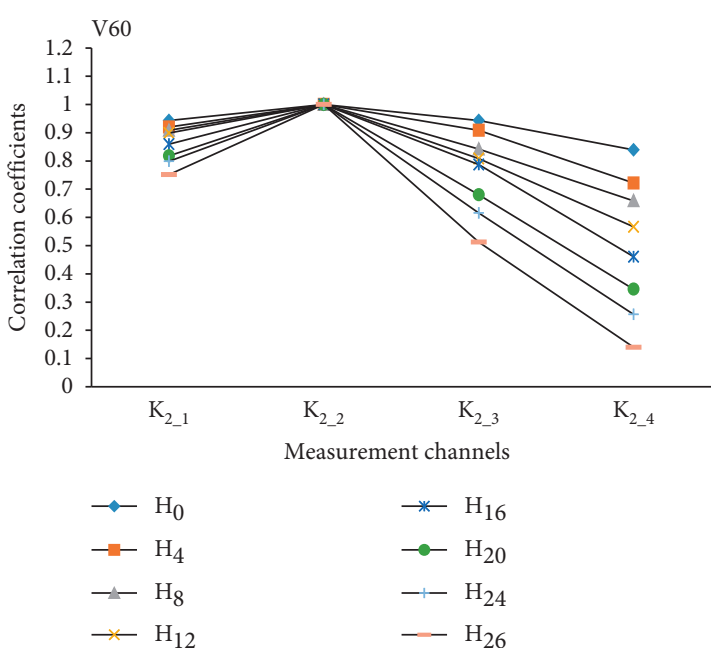

(b)

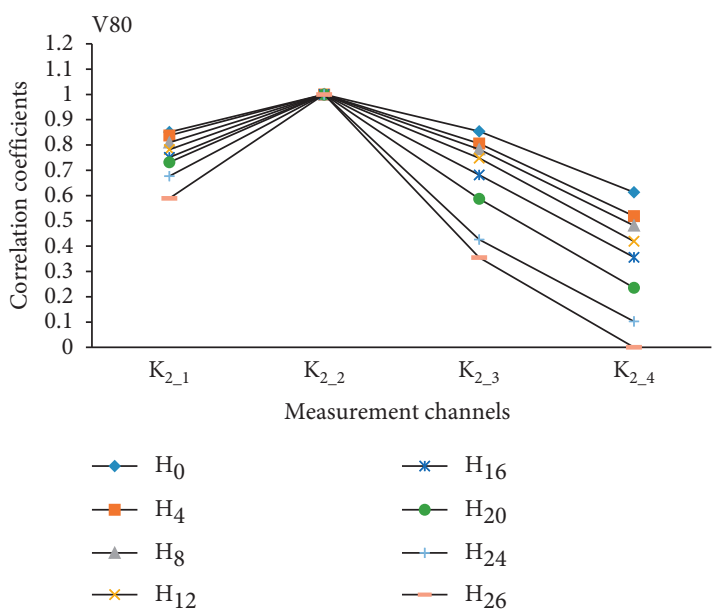

(d)

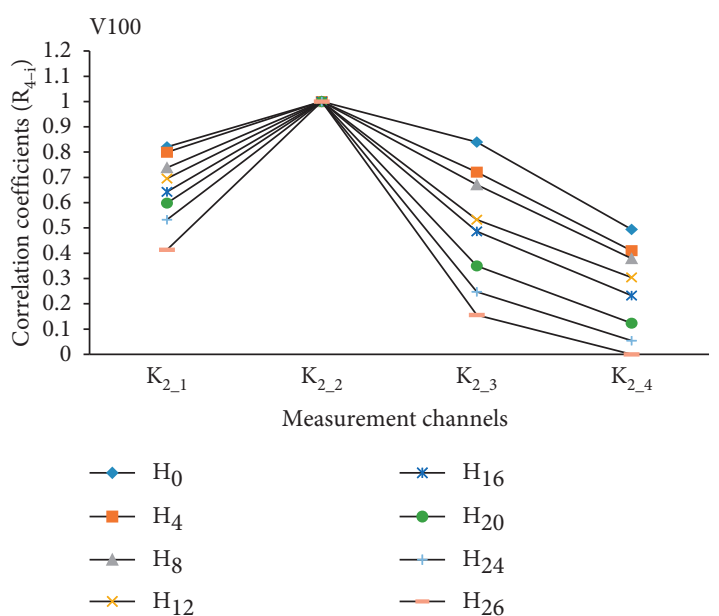

(f)

FIGURE 16: Changes of correlation coefficients $\mathrm{R}_{2-i}$ (between channel 2 and the remaining channels) corresponding to the levels of defects and different velocities.

experienced maximum loss when passing by the defect location. However, the correlation coefficients of $\left(\mathrm{R}_{1-3}\right)$ had lower energy loss because the distance between channel 1 and the defect location was large. When it passed the defect location, the remaining energy was not large enough to result in 

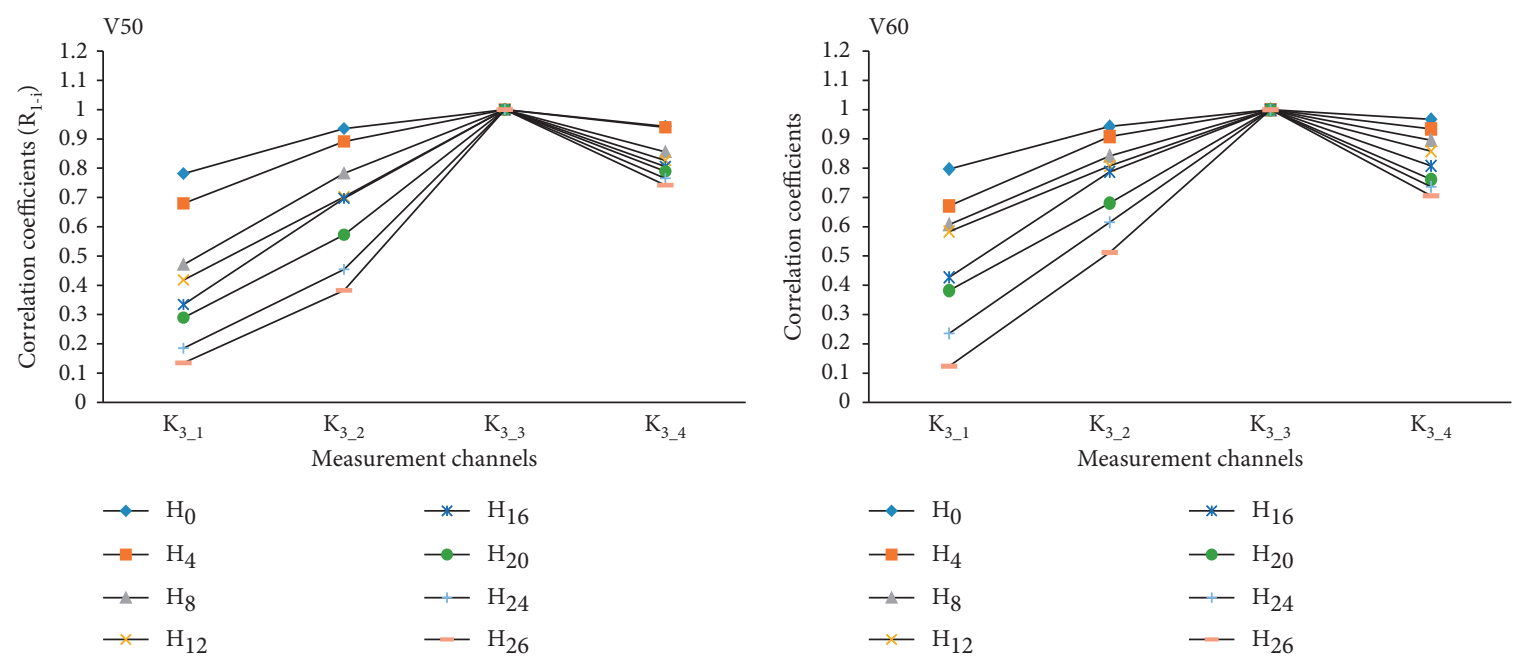

(a)
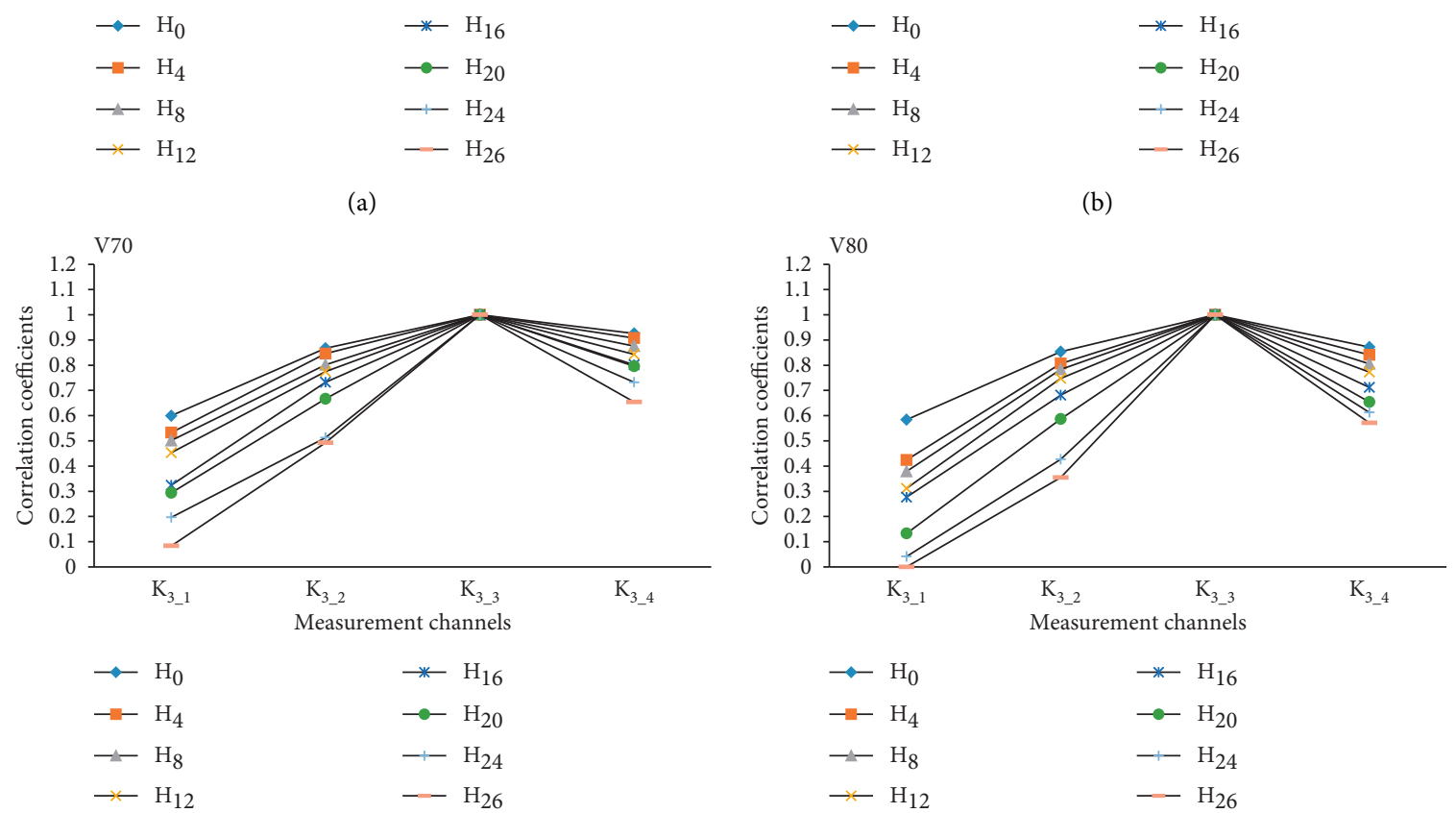

(b)

(c)

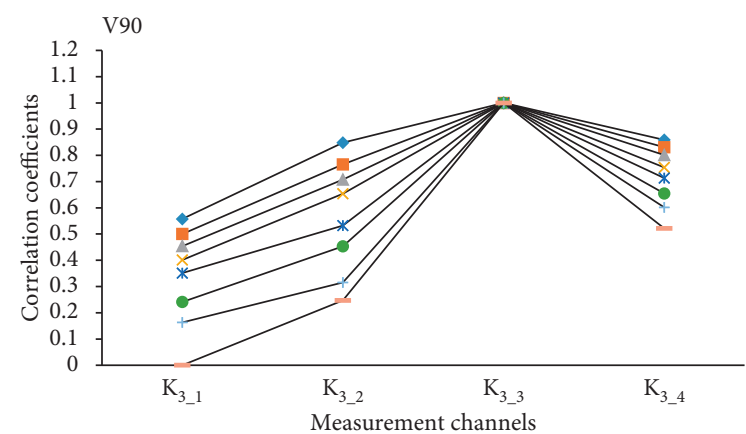

$$
\begin{array}{ll}
\rightarrow-\mathrm{H}_{0} & \rightarrow-\mathrm{H}_{16} \\
\rightarrow-\mathrm{H}_{4} & \rightarrow-\mathrm{H}_{20} \\
\rightarrow-\mathrm{H}_{8} & --\mathrm{H}_{24} \\
\rightarrow \leftarrow \mathrm{H}_{12} & --\mathrm{H}_{26}
\end{array}
$$

(d)

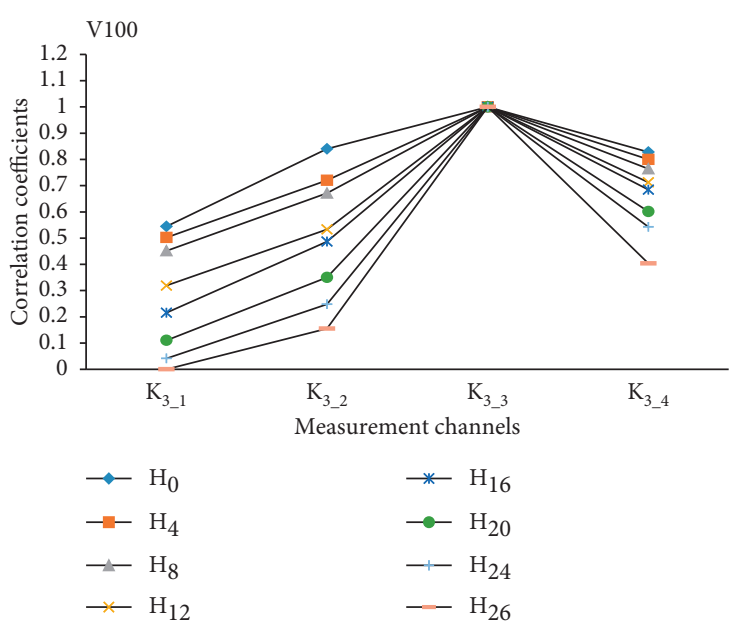

(f)

Figure 17: Changes of correlation coefficients $\mathrm{R}_{3-i}$ (between channel 3 and the remaining channels) corresponding to the levels of defects and different velocities. 

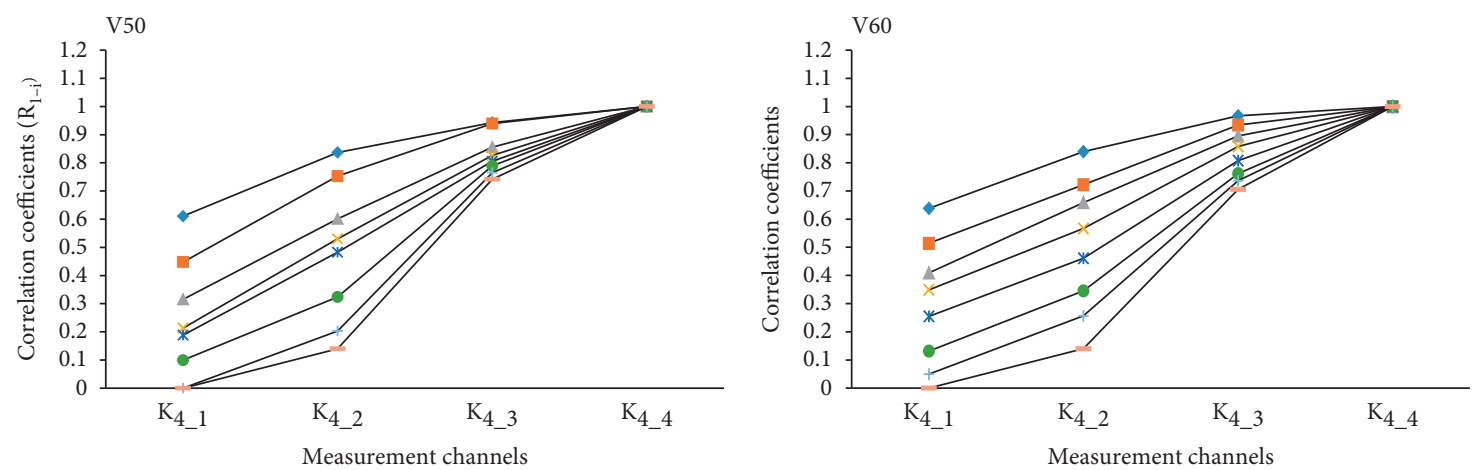

$$
\begin{array}{ll}
\rightarrow-\mathrm{H}_{0} & \rightarrow-\mathrm{H}_{16} \\
\rightarrow-\mathrm{H}_{4} & \rightarrow-\mathrm{H}_{20} \\
\rightarrow-\mathrm{H}_{8} & --\mathrm{H}_{24} \\
\rightarrow \leftarrow \mathrm{H}_{12} & --\mathrm{H}_{26}
\end{array}
$$

(a)

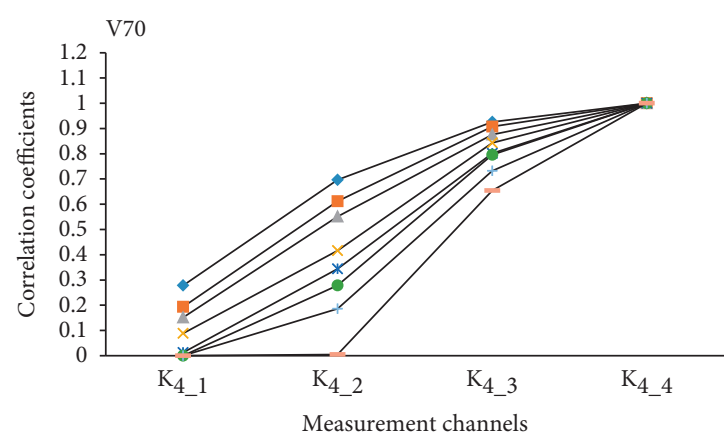

$$
\begin{array}{ll}
\rightarrow-\mathrm{H}_{0} & \rightarrow-\mathrm{H}_{16} \\
\rightarrow-\mathrm{H}_{4} & \rightarrow-\mathrm{H}_{20} \\
\rightarrow-\mathrm{H}_{8} & --\mathrm{H}_{24} \\
\rightarrow \leftarrow \mathrm{H}_{12} & --\mathrm{H}_{26}
\end{array}
$$

(c)

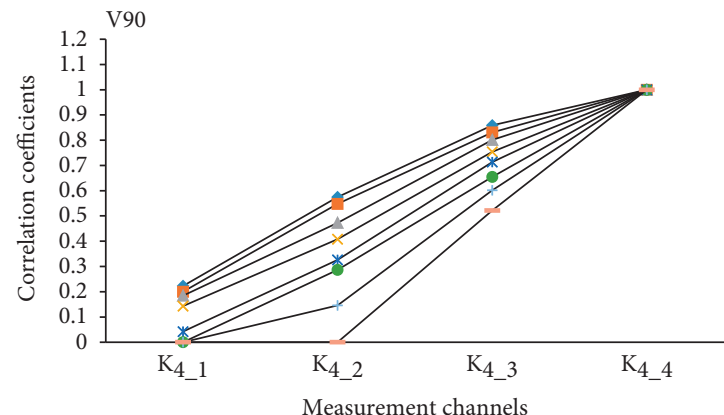

$$
\begin{array}{ll}
\rightarrow-\mathrm{H}_{0} & \rightarrow-\mathrm{H}_{16} \\
\rightarrow-\mathrm{H}_{4} & \rightarrow-\mathrm{H}_{20} \\
\rightarrow-\mathrm{H}_{8} & --\mathrm{H}_{24} \\
\rightarrow \leftarrow \mathrm{H}_{12} & --\mathrm{H}_{26}
\end{array}
$$

(e)

$$
\begin{array}{ll}
\rightarrow-\mathrm{H}_{0} & \rightarrow-\mathrm{H}_{16} \\
\rightarrow-\mathrm{H}_{4} & \rightarrow-\mathrm{H}_{20} \\
--\mathrm{H}_{8} & --\mathrm{H}_{24} \\
\rightarrow-\mathrm{H}_{12} & --\mathrm{H}_{26}
\end{array}
$$

(b)

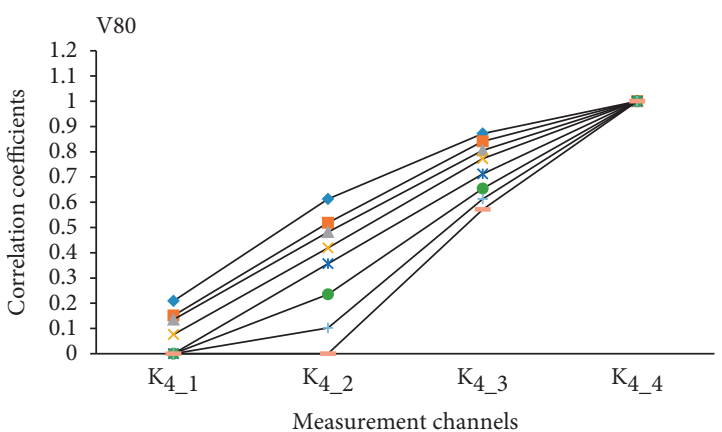

$$
\begin{array}{ll}
\rightarrow-\mathrm{H}_{0} & *-\mathrm{H}_{16} \\
\rightarrow-\mathrm{H}_{4} & \rightarrow-\mathrm{H}_{20} \\
\rightarrow-\mathrm{H}_{8} & -1-\mathrm{H}_{24} \\
\rightarrow \leftarrow \mathrm{H}_{12} & --\mathrm{H}_{26}
\end{array}
$$

(d)

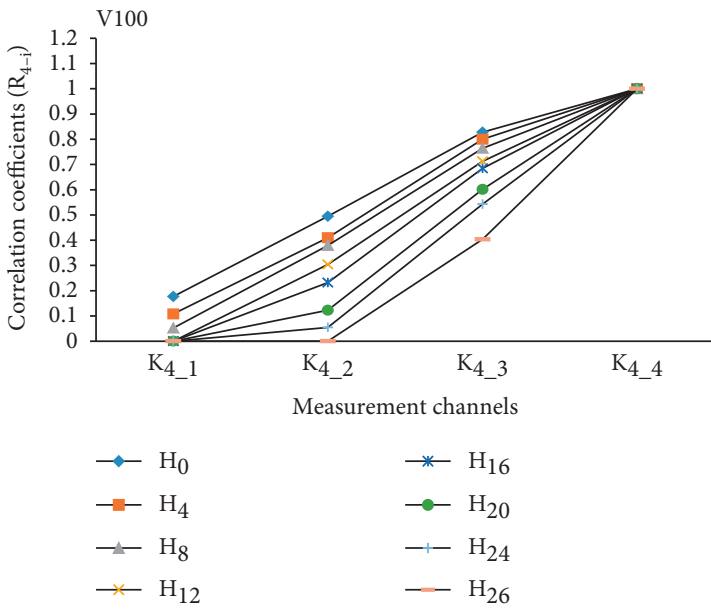

(f)

FIGURE 18: Changes of correlation coefficients $\mathrm{R}_{4-i}$ (between channel 4 and the remaining channels) corresponding to the levels of defects and different velocities. 


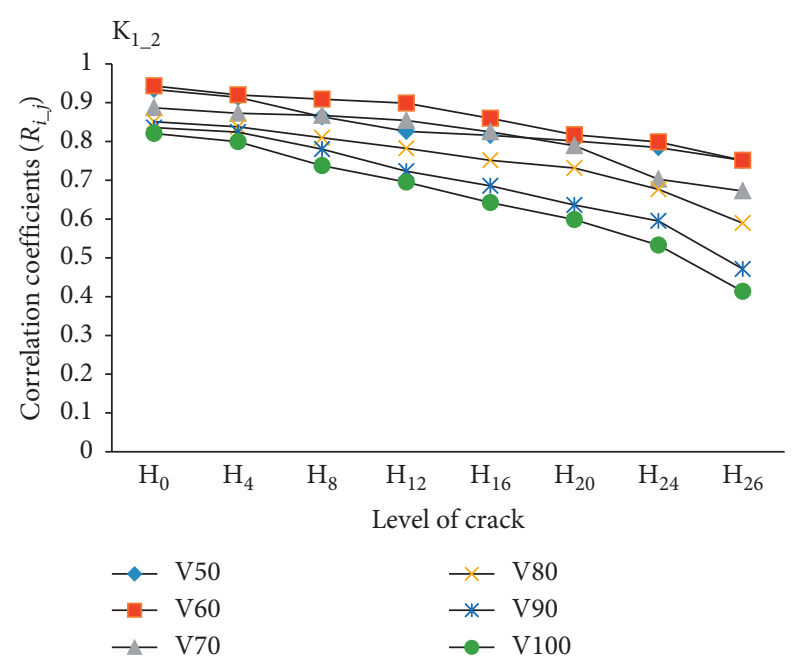

(a)

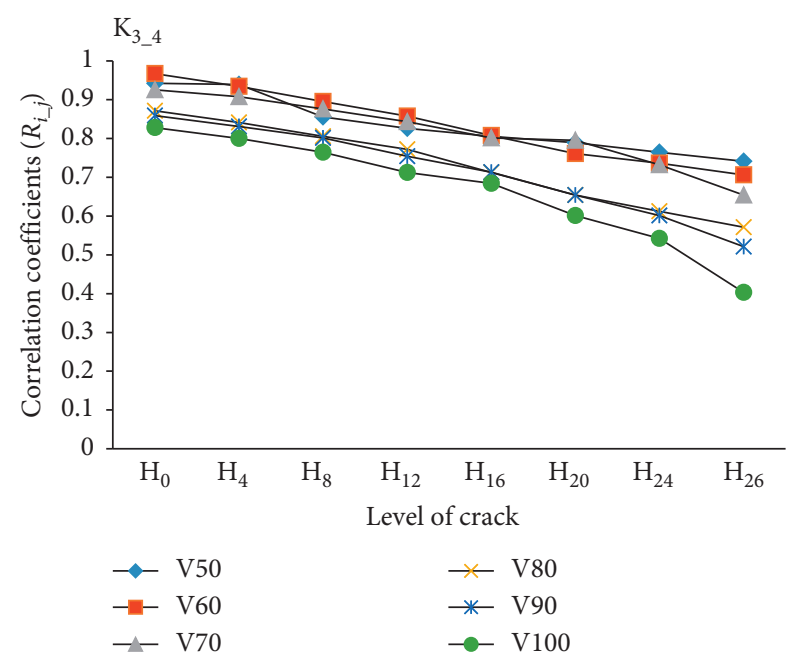

(b)

FIGURE 19: Relation between correlation coefficients of two consecutive channels $\left(\mathrm{R}_{1-2}\right.$ and $\left.\mathrm{R}_{3-4}\right)$ without cracks and the levels of cracks.

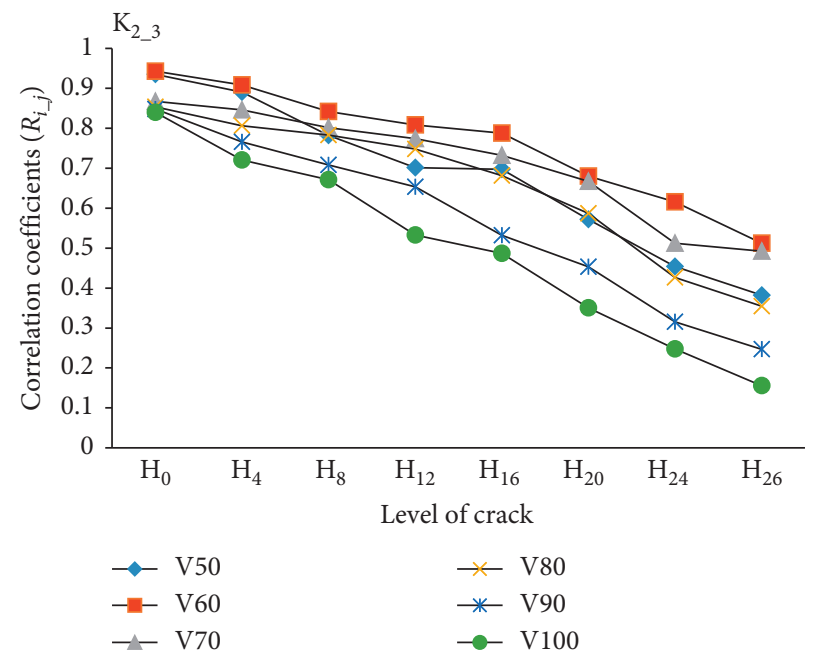

Figure 20: Relation between correlation coefficients of two consecutive channels $\left(R_{2-3}\right)$ with cracks and the levels of cracks.

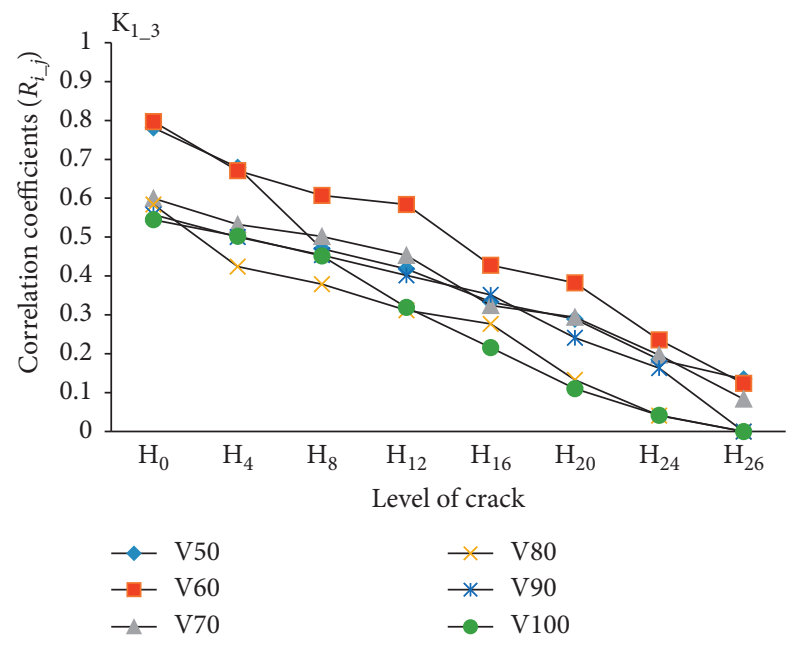

(a)

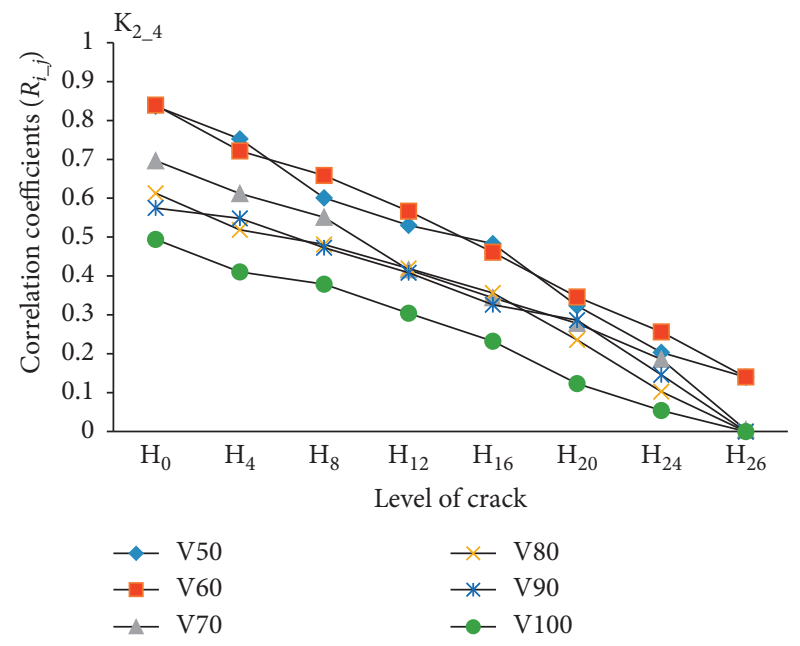

(b)

Figure 21: Relation between correlation coefficients of two channels $\left(\mathrm{R}_{1-3}\right.$ and $\left.\mathrm{R}_{2-4}\right)$ with cracks and the levels of cracks. 


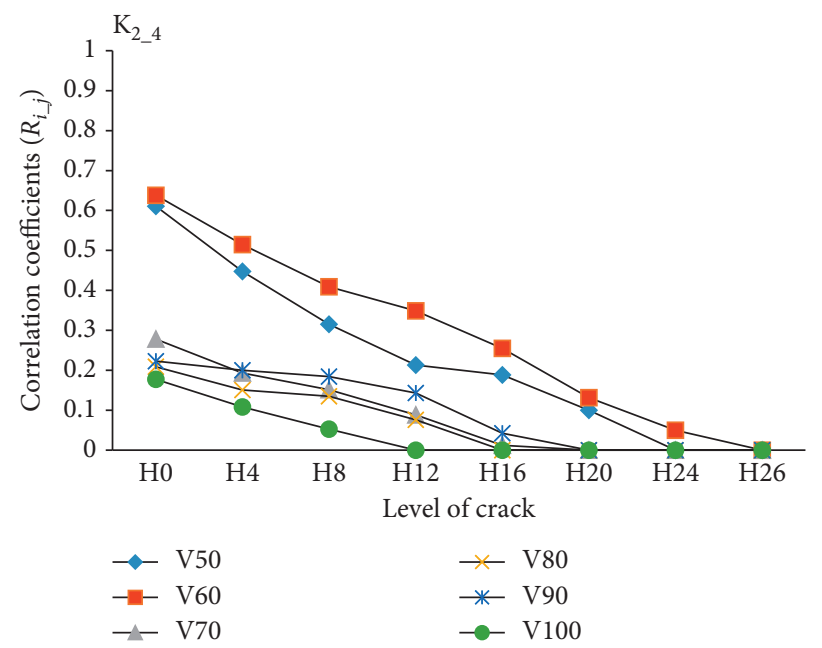

FIGURE 22: Relation between correlation coefficients of two channels $\left(\mathrm{R}_{1-4}\right)$ with cracks and the levels of cracks.
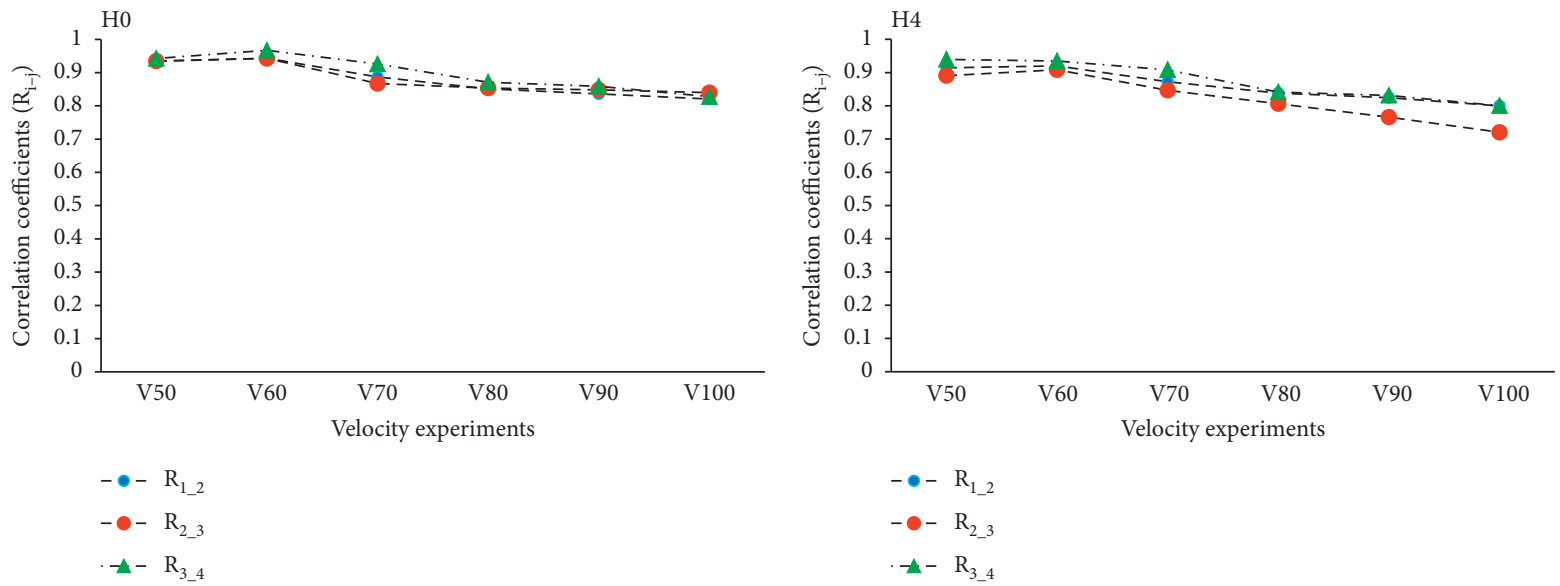

(a)
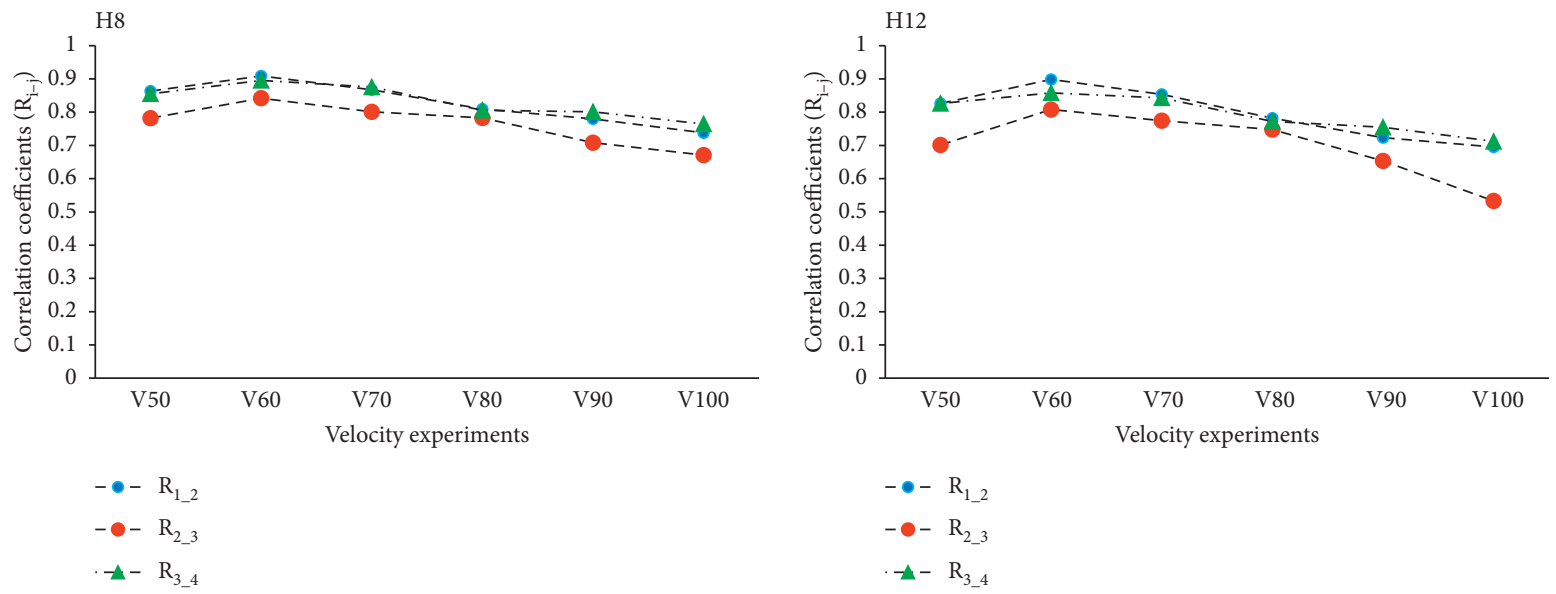

(c)

(d)

FIGURE 23: Continued. 

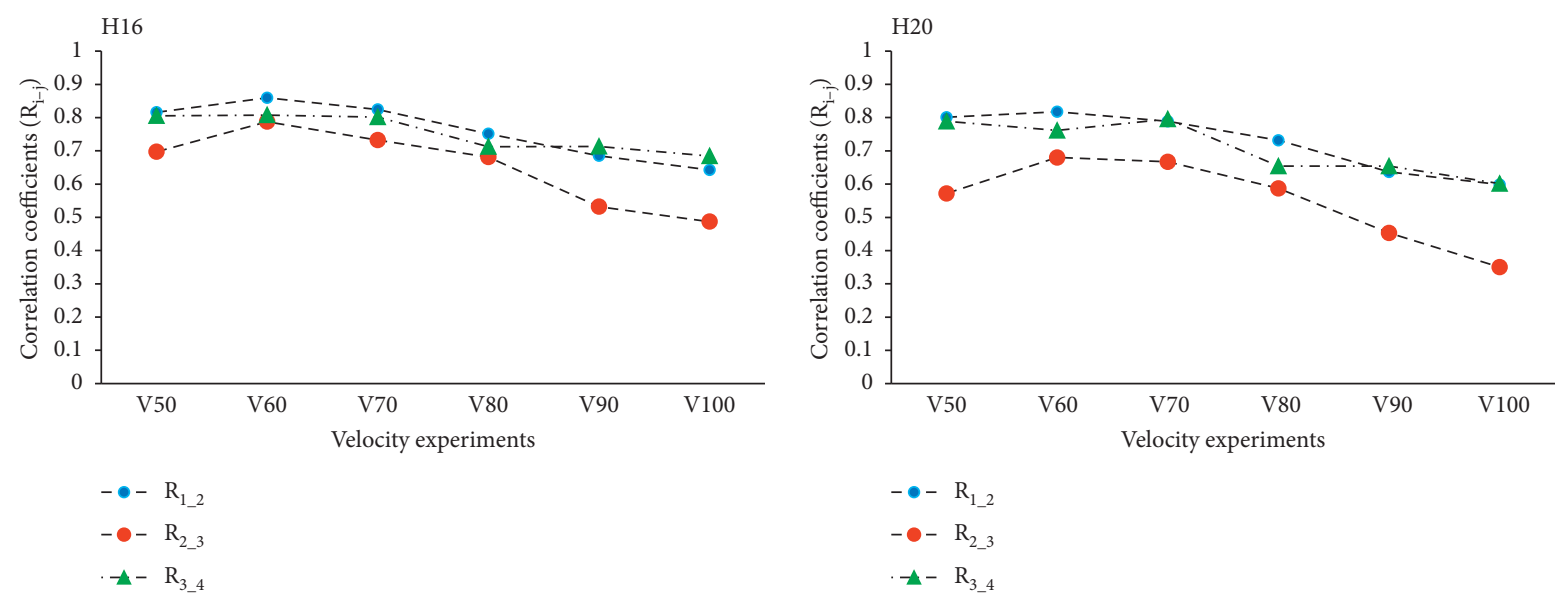

(e)
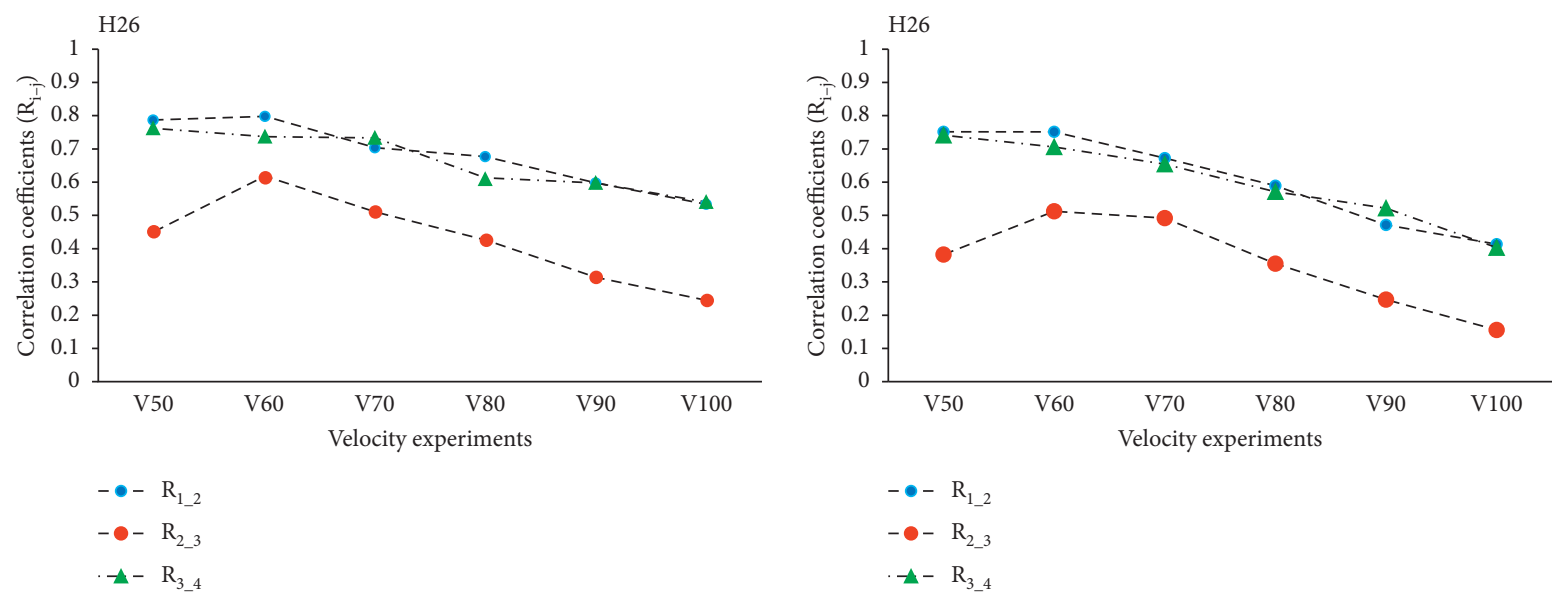

(g)

(h)

FIGURE 23: Relation between velocity and correlation coefficient values.

such a significant loss. Contrary to $\left(\mathrm{R}_{1-3}\right)$, the correlation value of $\left(\mathrm{R}_{2-4}\right)$ clearly increased at each level of defects. This meant that the distance between the measurement point of channel 2 and the defect location was shorter, causing more significant losses. We can immediately notice the impact of defects on the correlation coefficients.

Figure 22 shows the changes in the correlation coefficient values at different levels of defects in the beam. This is evidence that affirms the sensitivity of this parameter to defects. These changes, compared with the changes in natural frequency values and damping coefficients, are relatively large. Therefore, they support the application of this coefficient for detecting and evaluating defects in structures.

4.3.3. The Impact of Velocity on Correlation Coefficients and the Development of Defects. Velocity has a significant impact on changes in correlation coefficient values at different levels of defects in beams. In order to simplify the evaluation process, this study only investigated a case of two consecutive channels with the presence of $\left(R_{2-3}\right)$ or the absence of $\left(\mathrm{R}_{1-2}\right.$ and $\left.\mathrm{R}_{3-4}\right)$ defects. The results show that

(i) For intact beams (beams without defects), as shown in Figure 23(a), or beams with some defects (H4, H8, $\mathrm{H} 12)$, as in Figure 23(b), the impact of velocity was insignificant. The defect was not enough to reduce the correlation coefficients. The impact of velocity shows that the energy consumed when passing through the defect location is small.

(ii) On the contrary, at the high scale of defects, the impact of velocity was more significant. Figures 23(e)-23(h) show that the higher the velocity, the more energy in the beam. However, the higher the levels of defects, the more energy is lost. Thus, there is a large difference in energy loss between intact beams and defective beams, which is an important point to evaluate in the study of defects in beams.

\section{Conclusion}

In this research, we proposed a new parameter-the correlation coefficient - to detect and evaluate defects in beams. 
It is much more sensitive to defects than the natural frequency or the damping coefficient. This research has raised four prominent points:

(i) The natural frequency values in the experimental model were not sensitive enough to detect defects in the beam. The changes in this value were too small compared to the development of defects. Therefore, natural frequency measurements hardly meet the requirements of detecting defects in structures.

(ii) Although the damping coefficient had more variation than the natural frequency value in the same experiment, its changes were also insufficient and unstable at different levels of defects. Therefore, it is difficult to apply the damping coefficient method to detect the existence of defects, especially in beams suffering from major defects. In addition, changes in the damping coefficients at four measurement channels were relatively the same, so this characteristic makes it hard to locate cracks in the beam. Thus, the damping coefficient is still a low-sensitivity parameter that is difficult to apply.

(iii) The new proposed parameter has a linear characteristic and always significantly changes according to increasing levels of defects. The results show that the measurability of the changes using this method outweighs those from damping coefficient and natural frequency values. Furthermore, this value is always sensitive to measurement channels, which could be an important factor in locating defects in beams.

(iv) However, this research has limited value for investigating the relation between correlation coefficients and changes in beam stiffness due to cracks. Future research needs to be conducted to look into the quantitative evaluation of correlation coefficients to clarify that relation in the monitoring and identification of defects in structures.

\section{Data Availability}

All data generated or analysed during this study are included in this published article.

\section{Conflicts of Interest}

The authors declare that they have no conflicts of interest.

\section{Acknowledgments}

The authors wish to thank various people for their contribution towards this work. Mr. Lam Q. Tran and Mr Vien N. Le contributed for technical support on this project. Prof. Nhi K. Ngo, staff of Applied Mechanics (LAM), Ho Chi Minh City University of Technology, contributed in collecting the plant data and all the technicians helped in handling the instruments. The authors would like to specially thank Prof. Nhi K. Ngo, research project supervisor, for her professional guidance and valuable support and constructive recommendations on this project.

\section{References}

[1] G. Bhardwaj, I. V. Singh, and B. K. Mishra, "Stochastic fatigue crack growth simulation of interfacial crack in bi-layered FGMs using XIGA," Computer Methods in Applied Mechanics and Engineering, vol. 284, pp. 186-229, 2015.

[2] B. Kunin, "Stochastic model of brittle crack growth under cyclic load," International Journal of Pure and Applied Mathematics, vol. 84, no. 3, pp. 163-174, 2013.

[3] X. Yan, "A boundary element modeling of fatigue crack growth in a plane elastic plate," Mechanics Research Communications, vol. 33, no. 4, pp. 470-481, 2006.

[4] T. Belytschko and T. Black, "Elastic crack growth in finite elements with minimal remeshing," International Journal for $\mathrm{Nu}$ merical Methods in Engineering, vol. 45, no. 5, pp. 601-620, 1999.

[5] T. Rabczuk and T. Belytschko, "Cracking particles: a simplified meshfree method for arbitrary evolving cracks," International Journal for Numerical Methods in Engineering, vol. 61, no. 13, pp. 2316-2343, 2004.

[6] T. Rabczuk and T. Belytschko, "A three dimensional large deformation meshfree method for arbitrary evolving cracks," Computer Methods in Applied Mechanics and Engineering, vol. 196, no. 29-30, pp. 2777-2799, 2007.

[7] H. Yu, L. Wu, L. Guo, H. Wu, and S. Du, "An interaction integral method for 3D curved cracks in nonhomogeneous materials with complex interfaces," International Journal of Solids and Structures, vol. 47, no. 16, pp. 2178-2189, 2010.

[8] T. N. Bittencourt, P. A. Wawrzynek, A. R. Ingraffea, and J. L. Sousa, "Quasi-automatic simulation of crack propagation for 2D LEFM problems," Engineering Fracture Mechanics, vol. 55, no. 2, pp. 321-334, 1996.

[9] R. J. Price and J. Trevelyan, "Boundary element simulation of fatigue crack growth in multi-site damage," Engineering Analysis with Boundary Elements, vol. 43, pp. 67-75, 2014.

[10] N. Moës, J. Dolbow, and T. Belytschko, "A finite element method for crack growth without re-meshing," International Journal for Numerical Methods in Engineering, vol. 46, no. 1, pp. 131-150, 1999.

[11] K. Tanaka, "Fatigue crack propagation from a crack inclined to the cyclic tensile axis," Engineering Fracture Mechanics, vol. 6, no. 3, pp. 493-498, 1974.

[12] Q. W. Zhang, "Statistical damage identification for bridges using ambient vibration data," Computer and Structures, vol. 85, no. 7-8, pp. 476-485, 2007.

[13] Z. X. Li, T. H. T. Chan, and R. Zheng, "Statistical analysis of online strain response and its application in fatigue assessment of a long-span steel bridge," Engineering Structures, vol. 25, no. 14, pp. 1731-1741, 2003.

[14] A. Miyamoto, K. Kawamura, and H. Nakamura, "Bridge management system and maintenance optimization for existing bridges," Computer-Aided Civil and Infrastructure Engineering, vol. 15, no. 1, pp. 45-55, 2000.

[15] H. Furuta, J. He, and E. Watanabe, "A fuzzy expert system for damage assessment using genetic algorithms and neural networks," Computer-Aided Civil and Infrastructure Engineering, vol. 11, no. 1, pp. 37-45, 1996.

[16] C. Mares and C. Surace, "An application of genetic algorithms to identify damage in elastic structures," Journal of Sound and Vibration, vol. 195, no. 2, pp. 195-215, 1996.

[17] C.-B. Yun and E. Y. Bahng, "Substructural identification using neural networks," Computers \& Structures, vol. 77, no. 1, pp. 41-52, 2000. 
[18] C. C. Chang, T. Y. P. Chang, Y. G. Xu, and M. L. Wang, "Structural damage detection using an iterative neural network," Journal of Intelligent Material Systems and Structures, vol. 11 , no. 1 , pp. 32-42, 2000.

[19] C. S. Huang, S. L. Hung, C. M. Wen, and T. T. Tu, “A neural network approach for structural identification and diagnosis of a building from seismic response data," Earthquake Engineering \& Structural Dynamics, vol. 32, no. 2, pp. 187-206, 2003.

[20] X. Q. Zhu and S. S. Law, "Wavelet-based crack identification of bridge beam from operational deflection time history," International Journal of Solids and Structures, vol. 43, no. 7-8, pp. 2299-2317, 2006.

[21] E. Douka, S. Loutridis, and A. Trochidis, "Crack identification in beams using wavelet analysis," International Journal of Solids and Structures, vol. 40, no. 13-14, pp. 3557-3569, 2003.

[22] S. A. Ramu and V. T. Johnson, "Damage assessment of composite structures-A fuzzy logic integrated neural network approach," Computers \& Structures, vol. 57, no. 3, pp. 491-502, 1995.

[23] S. W. Doebling, C. R. Farrar, and M. B. Prime, "A summary review of vibration-based damage identification methods," The Shock and Vibration Digest, vol. 30, no. 2, pp. 91-105, 1998.

[24] S. W. Doebling, C. Farrar, M. B. Prime, and D. W. Shevitz, Damage Identification and Health Monitoring of Structural and Mechanical Systems from Changes in Their Vibration Characteristics: A Literature Review, Los Alamos National Laboratory, Los Alamos, New Mexico, 1996.

[25] A. Furukawa, H. Otsuka, and J. Kiyono, "Structural damage detection method using uncertain frequency response functions," Computer-Aided Civil and Infrastructure Engineering, vol. 21, no. 4, pp. 292-305, 2006.

[26] P. Cawley and R. D. Adams, "The location of defects in structures from measurements of natural frequencies," The Journal of Strain Analysis for Engineering Design, vol. 14, no. 2, pp. 49-57, 1979.

[27] N. T. Khiem and L. K. Toan, "A novel method for crack detection in beam-like structures by measurements of natural frequencies," Journal of Sound and Vibration, vol. 333, no. 18, pp. 4084-4103, 2014.

[28] O. S. Salawu, "Assessment of bridges: use of dynamic testing," Canadian Journal of Civil Engineering, vol. 24, no. 2, pp. 218-228, 1997.

[29] A. Shahdin, J. Morlier, and Y. Gourinat, "Damage monitoring in sandwich beams by modal parameter shifts: a comparative study of burst random and sine dwell vibration testing," Journal of Sound and Vibration, vol. 329, no. 5, pp. 566-584, 2010.

[30] J. C. Dodds Loland, "Experiment in developing and operating integrity," in Experiment in Developing and Operating Integrity, pp. 313-319, 1976.

[31] C. H. J. Fox, "The location of defects in structure: a compare of the use of natural frequency and mode shape data," in Proceedings of the 10th International Modal Analysis, pp. 522528, San Diego, California, 1992.

[32] U. Meneghetti and A. Maggiore, "Crack detection by sensitivity analysic," in Proceedings of the 12th International Modal Analysis Conference, pp. 1292-1298, Honolulu, HI, USA, January 1994.

[33] F. K. Choy, R. Liang, and P. Xu, "Fault identification of beams on elastic foundation," Computers and Geotechnics, vol. 17, no. 2, pp. 157-176, 1995.
[34] T. Q. Nguyen, T. T. D. Nguyen, H. Nguyen-Xuan, and N. K. Ngo, "A correlation coefficient approach for evaluation of stiffness degradation of beams under moving load," Computers, Materials and Continua, vol. 61, no. 1, pp. 27-53, 2019.

[35] T. Q. Nguyen, L. Q. Tran, H. Nguyen-Xuan, and N. K. Ngo, “A statistical approach for evaluating crack defects in structures under dynamic responses," Nondestructive Testing and Evaluation, p. 1, 2019.

[36] T. Q. Nguyen, H. C. Doan, L. C. Vuong, H. Nguyen-Xuan, and N. K. Ngo, "Fretting fatigue damage nucleation and propagation lifetime using a central point movement of power spectral density," Shock and Vibration, vol. 2020, no. 4, 16 pages, Article ID 4985134, 2020.

[37] Z. Yang, Z. Yu, and H. Sun, "On the cross correlation function amplitude vector and its application to structural damage detection," Mechanical Systems and Signal Processing, vol. 21, no. 7, pp. 2918-2932, 2007.

[38] F. Asma, "Damage detection by updating using correlation functions," Mechanical Engineering, vol. 73, no. 1, pp. 31-42, 2011.

[39] N. T. Khiem and T. V. Lien, "A simplified method for natural frequency analysis of a multiple cracked beam," Journal of Sound and Vibration, vol. 245, no. 4, pp. 737-751, 2001.

[40] N. T. Khiem and D. D. Khang, "Structural damage detection by measurements of vibration characteristics," in Proceedings of the International Operational Model Ananysis Conference, pp. 789-801, Portonovo, Italy, May 2009. 